\title{
Structural Studies of Perfluoroaryldiselenadiazolyl Radicals: Insights into Dithiadiazolyl Chemistry
}

\author{
Rebecca L. Melen, ${ }^{* \dagger, \dagger}$ Robert J. Less, ${ }^{\dagger}$ Christopher M. Pask, ${ }^{\dagger}$ and Jeremy M. Rawson ${ }^{*}, \dagger$, \\ ${ }^{\dagger}$ Department of Chemistry, University of Cambridge, Lensfield Road, Cambridge CB2 1EW, U.K. \\ ${ }^{\ddagger}$ School of Chemistry, Cardiff University, Main Building, Cardiff, CF10 3AT Cymru/Wales, U.K. \\ ${ }^{\S}$ Department of Chemistry and Biochemistry, University of Windsor, 401 Sunset Avenue, Windsor, Ontario N9B 3P4, Canada
}

\section{Supporting Information}

ABSTRACT: The synthesis and structural characterization of a series of perfluoroaryldiselenadiazolyls $\left[\mathrm{DSeDA} ; p-\mathrm{XC}_{6} \mathrm{~F}_{4} \mathrm{CNSeSeN}(\mathrm{X}=\mathrm{F}\right.$, $\mathrm{Cl}, \mathrm{Br}, \mathrm{CF}_{3}, \mathrm{NO}_{2}$, and $\mathrm{CN}$ for $\mathbf{2 a}-\mathbf{2 f}$, respectively)] are described. Concentration-dependent solution UV/vis measurements on $\mathbf{2 a}$ follow the Beer-Lambert law and the transitions assigned through timedependent density functional theory (TD-DFT) studies, indicating little propensity for dimerization in solution $\left(10^{-3}-10^{-4} \mathrm{M}\right)$. Solution electron paramagnetic resonance (EPR) spectra reveal that these
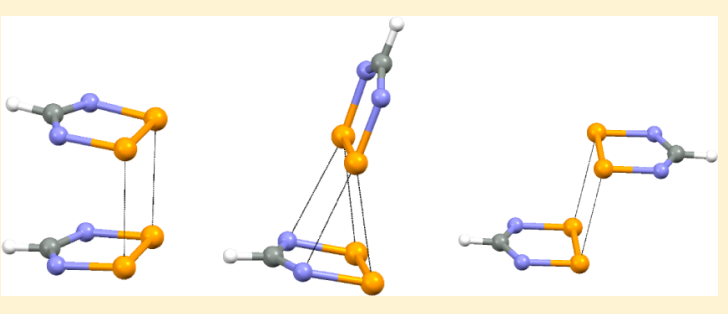
radicals exhibit a broad featureless singlet around $g=2.04$ but form well-resolved anisotropic EPR spectra in frozen solution, from which spin densities were determined and found to reflect an increase in the spin density at the chalcogen in relation to the corresponding dithiadiazolyl (DTDA) radicals, $p-\mathrm{XC}_{6} \mathrm{~F}_{4} \mathrm{CNSSN}$. The solid-state structures of $\mathbf{2 a}$ and $\mathbf{2 d - 2 f}$ all adopt spin-paired cis-cofacial dimers in which the dimers are held together via multicenter $\pi^{*}-\pi^{*}$ "pancake bonding" interactions. Conversely, $\mathbf{2 b}$ and $\mathbf{2 c}$ exhibit an orthogonal mode of association, which is unique to DSeDA chemistry but which also affords a singlet ground state evidenced by SQUID magnetometry. The more sterically demanding diselenadiazolyl radical $2 \mathrm{f}$ was also prepared and exhibits a trans-antarafacial dimerization mode. DFT studies [UPBE0-D3 ccPVTZ-PP(-F)++] on the model radical HCNSeSeN confirm that each dimer is a stable energy minimum on the potential energy surface, reproducing well the experimental geometric parameters with relative stability in the order ciscofacial $>$ orthogonal > trans-antarafacial. Computational studies reflect stronger dimerization for DSeDA radicals in relation to their sulfur analogues, consistent with the experimental observation: While $\mathbf{2} \mathbf{a}$ and $\mathbf{2} \mathbf{d}$ are isomorphous with their corresponding DTDA radicals, $\mathbf{2 b}, \mathbf{2 c}$, and $\mathbf{2 e - 2} \mathbf{g}$ are all dimeric, in contrast to their DTDA analogues, which are monomeric in the solid-state. A study on $\mathbf{2 f}$ reveals that significant geometric strain accumulates in order to support the propensity for both cis dimerization and intermolecular $\mathrm{CN} \cdots$ Se interactions. Conversely, $p-\mathrm{NCC}_{6} \mathrm{~F}_{4} \mathrm{CNSSN}$ likely forfeits dimerization in the analogous packing motif in order to release strain but retains the favorable intermolecular $\mathrm{CN} \cdots \mathrm{S}$ interactions.

\section{INTRODUCTION}

The magnetic ${ }^{1,2}$ and transport ${ }^{3}$ properties of dithiadiazolyl (DTDA) radicals have attracted considerable attention since the first structural report of a DTDA radical, $[\mathrm{PhCNSSN}]_{2}$, in $1980 .^{4}$ More recently, their coordination chemistry as paramagnetic ligands in molecule-based magnetic materials has been exploited by Preuss, ${ }^{5}$ and approaches to control their solid-state structure through crystal engineering design strategies have been reviewed by Haynes. ${ }^{6}$ In the majority of cases, these DTDA radicals adopt dimeric structures with short intradimer S...S contacts (ca. 3.0 $\AA$ ), which are significantly less than the sum of the van der Waals radii $(3.6 \AA)$ but more than a covalent $S-S$ bond $(2.0 \AA)$. Structural studies on these DTDA dimers reflect a range of dimerization modes (cis, twisted, trans etc.) in which there is a strong orientational preference, supporting the hypothesis that dimerization is associated with a bonding interaction between the two singly occupied molecular orbitals of $\mathrm{a}_{2}$ symmetry. The nature of the structure and bonding within these dimers continues to be a point of discussion. Initial descriptions by Banister and Gillespie favored a 4-center, 2-electron bonding interaction between the $S$ atoms, ${ }^{4,7}$ whereas Gleiter et al. utilized variously a 4-center, 6electron dimer or 14-electron $\sigma / \pi$-delocalized dimer description. ${ }^{8}$ Recent charge-density studies by Haynes et al. showed clear electron densities $\left(0.86-0.92\right.$ e $\left.\AA^{-3}\right)$ at the $S-S$ bond critical point, typical of a conventional covalent bond, but much lower electron densities at the intradimer $S \cdots S$ bond critical points $\left(0.14-0.17\right.$ e $\left.\AA^{-3}\right)$, consistent with a delocalized multicenter bonding interaction. ${ }^{9}$ More recent magnetic and electron paramagnetic resonance (EPR) studies by Passmore, Rawson, and their co-workers have revealed that many of these dimers exhibit the onset of paramagnetism near room temperature due to the population of a thermally accessible triplet state. ${ }^{10,11}$ This casts some speculation over the nature of the ground-state electronic configuration as to whether it is a closed-shell "spin-paired" singlet, an open-shell "antiferromagnetically coupled" singlet, or an admixture of these two

Received: July 27, 2016

Published: November 1, 2016 
possibilities. Computational studies suggest that the ground state has ca. $30 \%$ diradical character. ${ }^{12}$ These DTDA radicals comprise one member of a larger family of so-called "pancake dimers" in which the intermolecular contacts are much shorter than conventional van der Waals contacts and display a strong orientational dependence consistent with some degree of orbital interaction. ${ }^{13}$

The replacement of sulfur by selenium has several possible attractions. In the context of transport properties, Oakley et al. have shown that the replacement of sulfur by selenium often leads to isomorphous materials, with the selenium derivatives offering superior electron-transport properties due to the more radially diffuse nature of the $4 \mathrm{p}$ orbitals. ${ }^{14}$ Conversely, the development of selenium analogues of DTDA radicals as building blocks for organic magnetic materials has not been examined. In related thiazyl and selenazyl radical systems, the substitution of sulfur by selenium has led to stronger magnetic exchange coupling through the more diffuse nature of the $4 p$ valence orbitals of selenium as well as a larger magnetic anisotropy, ${ }^{15}$ which scales as $Z^{4}{ }^{16}$ In this context, the preparation and characterization of heavier p-block analogues of paramagnetic DTDA radicals appeared attractive, particularly given the seeming propensity for DSeDA radicals to adopt similar or isomorphous packing to their DTDA analogues. ${ }^{14}$ As an extension of our previous studies on perfluoroaryl and sterically encumbered DTDA radicals, ${ }^{1,2,17}$ we now describe the preparation and structural characterization of their heavier diselenadiazolyl, DSeDA, congeners, $p-\mathrm{XC}_{6} \mathrm{~F}_{4} \mathrm{CNSeSeN}(\mathrm{X}=$ $\mathrm{F}, \mathrm{Cl}, \mathrm{Br}, \mathrm{CF}_{3}, \mathrm{NO}_{2}$, and $\mathrm{CN}$ for $\mathbf{2 a - 2 f}$, respectively) and 2,4,6$\left(\mathrm{F}_{3} \mathrm{C}\right)_{3} \mathrm{C}_{6} \mathrm{~F}_{2} \mathrm{CNSeSeN}$ (2g; Scheme 1).

Scheme 1. General Synthetic Route to Novel Diselenadiazolyls $2 \mathrm{a}-\mathbf{2 g}$

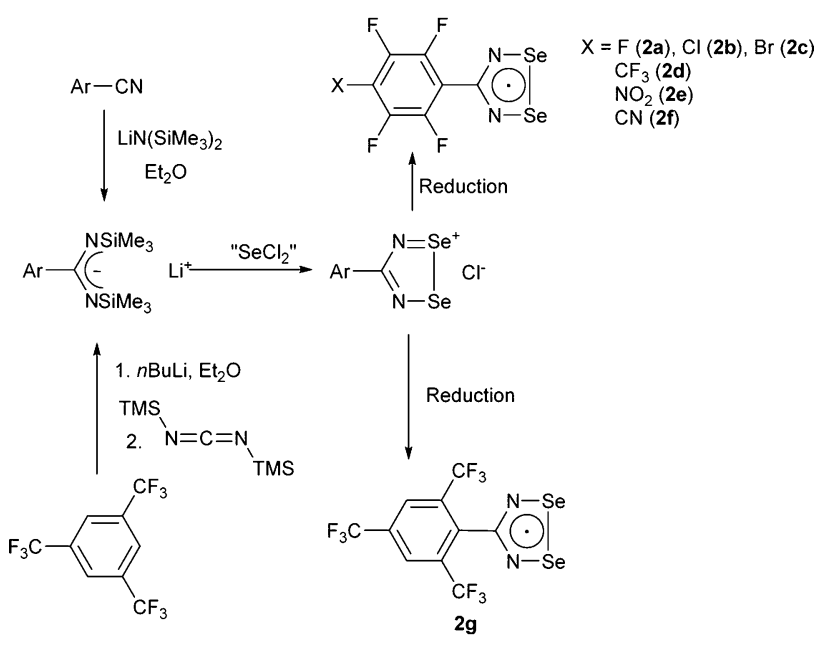

\section{RESULTS AND DISCUSSION}

The synthesis of the diselenadiazolyl radicals $\mathbf{2 a}-\mathbf{2} \mathbf{f}$ followed a method similar to that used to prepare the related DTDA radicals using a mixture of $\mathrm{SeCl}_{4}$ and elemental selenium as a source of $\mathrm{SeCl}_{2}$ (Scheme 1). ${ }^{18}$ This source of $\mathrm{SeCl}_{2}$ is preferred over a 1:1 mixture of $\mathrm{Ph}_{3} \mathrm{Sb}$ and $\mathrm{SeCl}_{4}$, which, in our hands, has, on occasion, been violently exothermic when mixed together in the solid state. Reduction of the sparingly soluble chloride salt [2] Cl was readily achieved via one-electron reduction in a polar solvent. Assorted reducing agents (silver powder, $\mathrm{Zn} / \mathrm{Cu}$ couple, or $\mathrm{Ph}_{3} \mathrm{Sb}$ ) in a range of polar solvents [acetonitrile
$(\mathrm{MeCN})$, tetrahydrofuran (THF), or liquid $\mathrm{SO}_{2}$ ) proved successful in driving the one-electron reduction, evidenced by the color change to deep purple and the appearance of an EPR signal. However, separation of the radical from the solvent and byproducts proved problematic. The use of silver powder in THF proved successful for both $\mathbf{2 b}$ and $\mathbf{2 e}$ but, in other cases, formed oily residues from which pure radical could not be isolated by sublimation. The use of $\mathrm{Ph}_{3} \mathrm{Sb}$ in $\mathrm{MeCN}$ as an alternative reductant can be successfully (2a, $2 c$, and $2 \mathrm{f}$ ) used provided the radical does not sublime at temperatures similar to those of $\mathrm{Ph}_{3} \mathrm{Sb}\left(\mathrm{mp} \mathrm{52}-54{ }^{\circ} \mathrm{C}\right)$, which can contaminate the sample or lead to cocrystallization. ${ }^{19}$ For volatile radicals or those with a high solvent affinity, the use of $\mathrm{Zn} / \mathrm{Cu}$ couple in highly volatile liquid $\mathrm{SO}_{2}$ proved successful ( $2 \mathrm{~d}$ and $\mathbf{2 g}$ ).

Radical $2 \mathrm{~g}$ was prepared using a method analogous to the preparation of the sulfur analogue. ${ }^{17 \mathrm{c}}$ The crude diselenadiazolyl radicals $(\mathbf{2} \mathbf{a}-\mathbf{2} \mathbf{g})$ were purified by vacuum sublimation in glass tubes with crystals of $\mathbf{2 a - 2} \mathbf{g}$ grown by vacuum sublimation under static vacuum $\left(10^{-1}\right.$ Torr $)$. Yields were not optimized for these predominantly structural studies but were up to $54 \%$ recovered yield based on the starting material.

Solution Studies on 2. Unlike DTDA radicals, which exhibit well-resolved solution EPR spectra $\left(g=2.01\right.$ and $a_{\mathrm{N}} \sim$ $5.0 \mathrm{G})$, the EPR spectra of 2 in THF were observed as broad singlets at $g=2.04$ (see the Supporting Information, SI). Similar spectra were observed at low concentration, indicating that this was not due to dipolar broadening effects but was the result of significant g-tensor anisotropy (vide infra), consistent with previous observations. ${ }^{18,20}$ However, frozen-solution spectra provided well-resolved features reflecting rhombic symmetry, and the frozen-solution EPR spectrum of $\mathbf{2 b}$ is shown in Figure 1. The EPR spectrum reveals well-resolved hyperfine coupling to two ${ }^{14} \mathrm{~N}$ nuclei of the $g_{x x}$ component of the spectrum, and ${ }^{77} \mathrm{Se}$ satellites for both $g_{x x}$ and $g_{z z}$ were directly observed with estimates of additional hyperfine couplings based on the fit to the EPR profile. These parameters are compared with those of $\mathrm{C}_{6} \mathrm{~F}_{5} \mathrm{CNSSN}^{21}$ in Table 1 . The

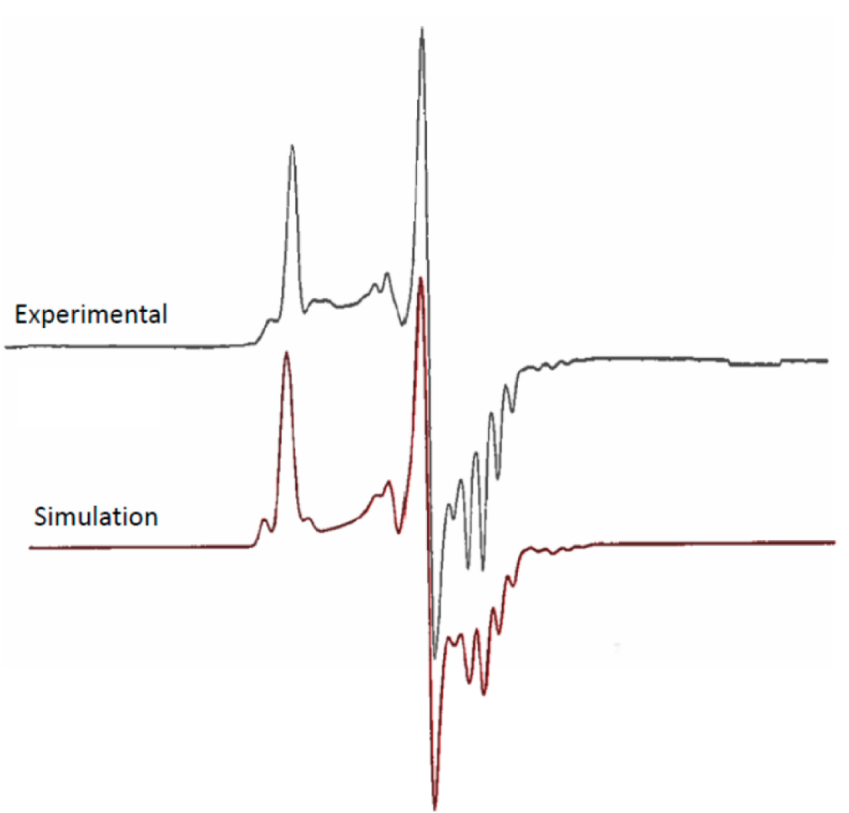

Figure 1. Frozen-solution EPR spectrum of $\mathbf{2 b}$ in THF at $77 \mathrm{~K}$. Simulation parameters are given in Table 1. 
Table 1. EPR Simulation Parameters for $2 b$ (Line Width = $\left.3.2 \mathrm{G}_{\mathrm{pp}}\right)$ and for $\mathrm{C}_{6} \mathrm{~F}_{5} \mathrm{CNSSN}^{21}$

\begin{tabular}{|c|c|c|c|c|c|}
\hline parameter & $g_{x x}$ & $g_{y y}$ & $g_{z z}$ & $\langle g\rangle$ & $g_{\text {iso }}$ \\
\hline $2 b$ & 1.9828 & 2.0214 & 2.1001 & 2.0346 & 2.0376 \\
\hline $\mathrm{C}_{6} \mathrm{~F}_{5} \mathrm{CNSSN}$ & 2.0025 & 2.0085 & 2.0220 & 2.0110 & 2.0102 \\
\hline parameter & $\begin{array}{c}A(\mathrm{~N})+ \\
A_{x x}(\mathrm{~N}) / G\end{array}$ & $\begin{array}{c}A(\mathrm{~N})+ \\
A_{y y}(\mathrm{~N}) / G\end{array}$ & $\begin{array}{c}A(\mathrm{~N})+ \\
A_{z z}(\mathrm{~N}) / G\end{array}$ & $\langle a(\mathrm{~N})\rangle / G$ & $a(\mathrm{~N}) / G$ \\
\hline $2 b$ & 13.67 & 2.00 & 1.33 & 5.67 & \\
\hline $\mathrm{C}_{6} \mathrm{~F}_{5} \mathrm{CNSSN}$ & 13.84 & 1.00 & 0.31 & 5.05 & 5.17 \\
\hline parameter & $\begin{array}{c}A(\mathrm{Se})+ \\
A_{x x}(\mathrm{Se}) / G\end{array}$ & $\begin{array}{c}A(\mathrm{Se})+ \\
A_{y y}(\mathrm{Se}) / G\end{array}$ & $\begin{array}{c}A(\mathrm{Se})+ \\
A_{z z}(\mathrm{Se}) / G\end{array}$ & $\langle a(\mathrm{Se})\rangle / G$ & $a(\mathrm{Se}) / G$ \\
\hline $2 b$ & 130.66 & -56.00 & -3.87 & 23.6 & \\
\hline
\end{tabular}

absolute signs of the ${ }^{77}$ Se hyperfine interactions are not known, but the two smaller ${ }^{77}$ Se hyperfine couplings were considered opposite in sign to the largest coupling because ${ }^{77} \mathrm{Se}$ satellites beyond the line width of the isotropic EPR spectrum were not observed, consistent with previous reports on the isolobal $\mathrm{S}_{3} \mathrm{~N}_{2}{ }^{\bullet+}$ and $\mathrm{Se}_{2} \mathrm{~N}_{2} \mathrm{~S}^{\bullet+}$ radical cations. ${ }^{20}$ These spectral parameters were common across several derivatives of 2 . An estimate of the spin-density distribution in these DSeDA radicals can be made based on the EPR parameters and has proved successful in assessing the spin density in other thiazyl and selenazyl radicals. ${ }^{20}$ In the case of DTDA radicals, estimates of the spin-density distribution from EPR have been in very good agreement with measured spin densities determined from polarized neutron diffraction studies as well as density functional theory (DFT) calculations. ${ }^{22}$ These calculations (see the SI) provide total spin densities of $21 \%$ and $31 \%$ on the $\mathrm{N}$ and Se atoms, respectively (see the SI). Thus, replacement of sulfur by selenium leads to a small reduction in the spin density at $\mathrm{N}$ and an increase at the chalcogen in relation to DTDA radicals, a trend that has been previously observed for $\mathrm{S}_{3} \mathrm{~N}_{2}{ }^{\bullet+}$ and its selenium derivatives. ${ }^{20}$ A comparison of the spin densities from EPR and those from unrestricted DFT studies [PBE0-D3 cc-PVTZ-PP(-F)++] is presented in the SI.

Previous EPR studies on DTDA radicals revealed a monomer-dimer equilibrium in solution with $\Delta H_{\text {dim }} \sim 35 \mathrm{~kJ}$ $\mathrm{mol}^{-1}$ for a range of substituents. ${ }^{23}$ Additional solution $\mathrm{UV} / \mathrm{vis}$ studies by Preuss indicated that at concentrations below $10^{-3}$ $M$ the contributions from the dimer were negligible. ${ }^{24}$ The increased spin density at selenium appears to lead to greater dimerization in solution reflected in (i) many UV/vis transitions on PhCNSeSeN in THF exhibiting an absorbance that is proportional to the square of the concentration, at concentrations similar to those of the DTDA studies and (ii) an approximately estimated $70 \%$ dissociation by EPR. ${ }^{25}$

In order to examine the effect of the perfluoroaryl group on the monomer-dimer equilibrium, variable-concentration UV/ vis studies on $2 \mathrm{a}$ were undertaken in THF in the range $10^{-3}$ $10^{-4} \mathrm{M}$. The visible spectrum is dominated by a well-defined maximum at $369 \mathrm{~nm}$ with a shoulder at $433 \mathrm{~nm}$ in THF (Figure 2). These transitions exhibit a linear relationship between the absorbance and concentration (see the SI), indicating that these bands are associated with monomeric $2 \mathrm{a}$ in solution. In addition, time-dependent DFT (TD-DFT) calculations [UPBE0-D3 cc-PVTZ-PP(-F)++] on monomeric 2a replicate very well the salient intense features of the UV/vis data. Similar linear behavior would be observed if the monomer-dimer ratio did not change significantly over the concentration range studied. However, the good agreement between the observed and calculated UV/vis spectra coupled with previous

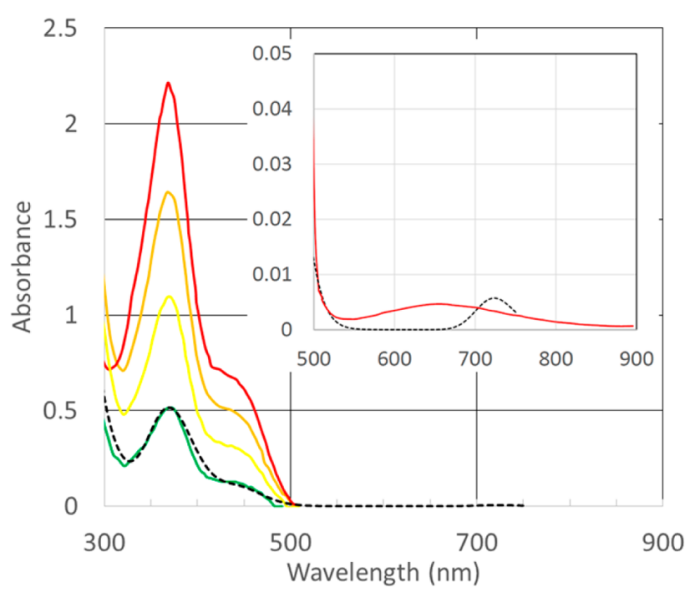

Figure 2. Solution UV/vis spectra of $2 \mathrm{a}$ in THF $\left(2.5 \times 10^{-4}, 5.0 \times\right.$ $10^{-4}, 7.5 \times 10^{-4}$, and $\left.1.0 \times 10^{-3} \mathrm{M}\right)$ with a calculated absorption profile (-- -). Inset: Detail of the low-energy region of the UV/vis spectrum with a calculated absorption profile $(-)$.

quantitative $\mathrm{EPR}$ studies on $[\mathrm{PhCNSeSeN}]_{2}$, which revealed at least $70 \%$ dissociation in solution, ${ }^{25}$ suggests that the solution UV/vis spectra are predominantly those of the monomer.

A very weak low-energy absorption at $650 \mathrm{~nm}$ is observed at high THF concentrations $\left(10^{-3} \mathrm{M}\right.$; Figure 2, inset). The broadness and low intensity of this transition inhibited a full analysis of its concentration dependence to distinguish between $\mathbf{2 a}$ and $(\mathbf{2 a})_{2}$. However, the TD-DFT studies on $\mathbf{2 a}$ reveal a weak transition around $720 \mathrm{~nm}$ that is associated with the promotion of the unpaired electron from the $\pi^{*}$ molecular orbital of $\mathrm{a}_{2}$ symmetry to the $\mathrm{Se}-\mathrm{Se} \sigma^{*}$ orbital, although we recognize that this does not preclude the broad transition also having a component arising from dimeric $(2 \mathbf{a})_{2}$.

Structural Studies. A summary of the crystallographic data for $\mathbf{2 a - 2} \mathbf{g}$ is presented in the SI, and selected structural data are presented in Table 2.

Crystal Structures of $\left(\mathrm{C}_{6} \mathrm{~F}_{5} \mathrm{CNSeSeN}\right)_{2} \quad(2 a)$, ( $p$ $\left.\mathrm{F}_{3} \mathrm{CC}_{6} \mathrm{~F}_{4} \mathrm{CNSeSeN}\right)_{2}(2 d),\left(p-\mathrm{O}_{2} \mathrm{NC}_{6} \mathrm{~F}_{4} \mathrm{CNSeSeN}\right)_{2}(2 e)$, and $(p-$ $\left.\mathrm{NCC}_{6} \mathrm{~F}_{4} \mathrm{CNSeSeN}\right)_{2}$ (2f). All four of these radicals exhibit ciscofacial dimers (Figure 3). The intradimer Se...Se contacts (Table 2) fall in the range $3.195(5)-3.275(5) \AA$ and are comparable with those of other cis-oid DSeDA derivatives (3.17-3.37 $\AA$; mean $3.26 \AA){ }^{26}$ The twist angles between perfluoroaryl and DSeDA rings $(\theta)$ fall in the range 34.6-42.0 comparable with those reported for perfluoroaryl DTDA radicals in which a shallow energy minimum has been computed around $50^{\circ}$ with angles in the range $20-90^{\circ}$ all within $5 \mathrm{~kJ} \mathrm{~mol}^{-1}$. $^{\circ}$ The angle formed between the two DSeDA ring planes $(\phi)$ spans a narrow range of $9.0-11.8^{\circ}$, and a degree of strain is observed through bending of the DSeDA ring from the phenylene plane to optimize the close approach of $\mathrm{DSeDA}$ rings in the dimer formation. A molecular bowing parameter $(\beta$; defined as the angle formed between the para substituent, the phenylene ring centroid, and the $C$ atom of the DSeDA ring) is used to provide a measure of the total molecular distortion of the substituent and the DSeDA ring from the phenylene ring plane. Deviations from $180^{\circ}$ reflect some distortion of the molecular structure. Structures $\mathbf{2 a}$ and $2 \mathrm{~d}-\mathbf{2 f}$ provide parameters in the range $173-178^{\circ}$, with cyano and nitro derivatives ( $\mathbf{e}$ and $\mathbf{2 f}$ ) exhibiting the largest distortions from $180^{\circ}$, suggesting a build-up of ring strain. 
Table 2. Intradimer Se $\cdots$ Se and Interdimer Se $\cdots$ N Contacts, Torsion Angles $(\theta)$ between DSeDA and the Aryl Ring Planes, Inclinations $(\phi)$ of DSeDA Ring Planes with Respect to Each Other, and Bowing Angles $(\beta)$ Defined as the Angle Made between the $\mathrm{R}$ Group, the Centroid of the Phenylene Ring, and the DSeDA Ring C Atom

\begin{tabular}{|c|c|c|c|c|c|c|}
\hline compound & intradimer $\mathrm{Se} \cdots \mathrm{Se} / \AA$ & intradimer Se $\cdots \mathrm{N} / \AA$ & $\theta / \operatorname{deg}$ & $\phi / \operatorname{deg}$ & $\beta / \operatorname{deg}$ & interdimer $\mathrm{Se} \cdots \mathrm{N} / \AA$ \\
\hline \multicolumn{7}{|c|}{ Cisoid Dimers } \\
\hline \multirow{2}{*}{$\mathbf{2 a}(\mathrm{X}=\mathrm{F})$} & $3.197(2)$ & & 38.8 & 9.68 & 176.95 & $3.092(6)$ \\
\hline & & & & & & $3.097(6)$ \\
\hline \multirow[t]{2}{*}{$2 d\left(X=C_{3}\right)$} & $3.200(1)$ & & 40.45 & 11.83 & 177.35 & $2.941(7)$ \\
\hline & $3.208(1)$ & & 42.03 & & 177.61 & $2.988(7)$ \\
\hline \multirow{2}{*}{$2 \mathbf{e}\left(\mathrm{X}=\mathrm{NO}_{2}\right)$} & $3.195(5)$ & & 34.65 & 10.68 & 173.55 & $3.06(3)$ \\
\hline & $3.275(5)$ & & 40.67 & & 176.90 & $3.26(3)$ \\
\hline \multirow[t]{2}{*}{$2 f(X=C N)$} & $3.212(2)$ & & 36.70 & 8.96 & 175.52 & $3.14(1)$ \\
\hline & $3.220(2)$ & & 36.78 & & 175.58 & $3.19(1)$ \\
\hline \multicolumn{7}{|c|}{ Orthogonal Dimers } \\
\hline \multirow[t]{2}{*}{$\mathbf{2 b}(\mathrm{X}=\mathrm{Cl})$} & $3.110(7)$ & $3.04(3)$ & 58.23 & 81.51 & 177.37 & $3.06(3)$ \\
\hline & $3.207(7)$ & $3.11(3)$ & 59.70 & & 177.29 & $3.25(3)$ \\
\hline \multirow[t]{2}{*}{$2 \mathrm{c}(\mathrm{X}=\mathrm{Br})$} & $3.115(6)$ & $3.04(3)$ & 56.34 & 84.36 & 177.80 & $3.02(2)$ \\
\hline & $3.187(6)$ & $3.06(3)$ & 59.01 & & 179.02 & $3.22(2)$ \\
\hline \multirow{4}{*}{$2 g$} & & Trans-Anta & Dimer & & & \\
\hline & $3.230(2)$ & & 75.83 & 7.59 & 177.65 & $2.840(9)$ \\
\hline & $3.316(1)$ & & 79.01 & 0.00 & 178.74 & $3.254(8)$ \\
\hline & $3.334(2)$ & & 89.70 & & 179.26 & $3.288(9)$ \\
\hline
\end{tabular}
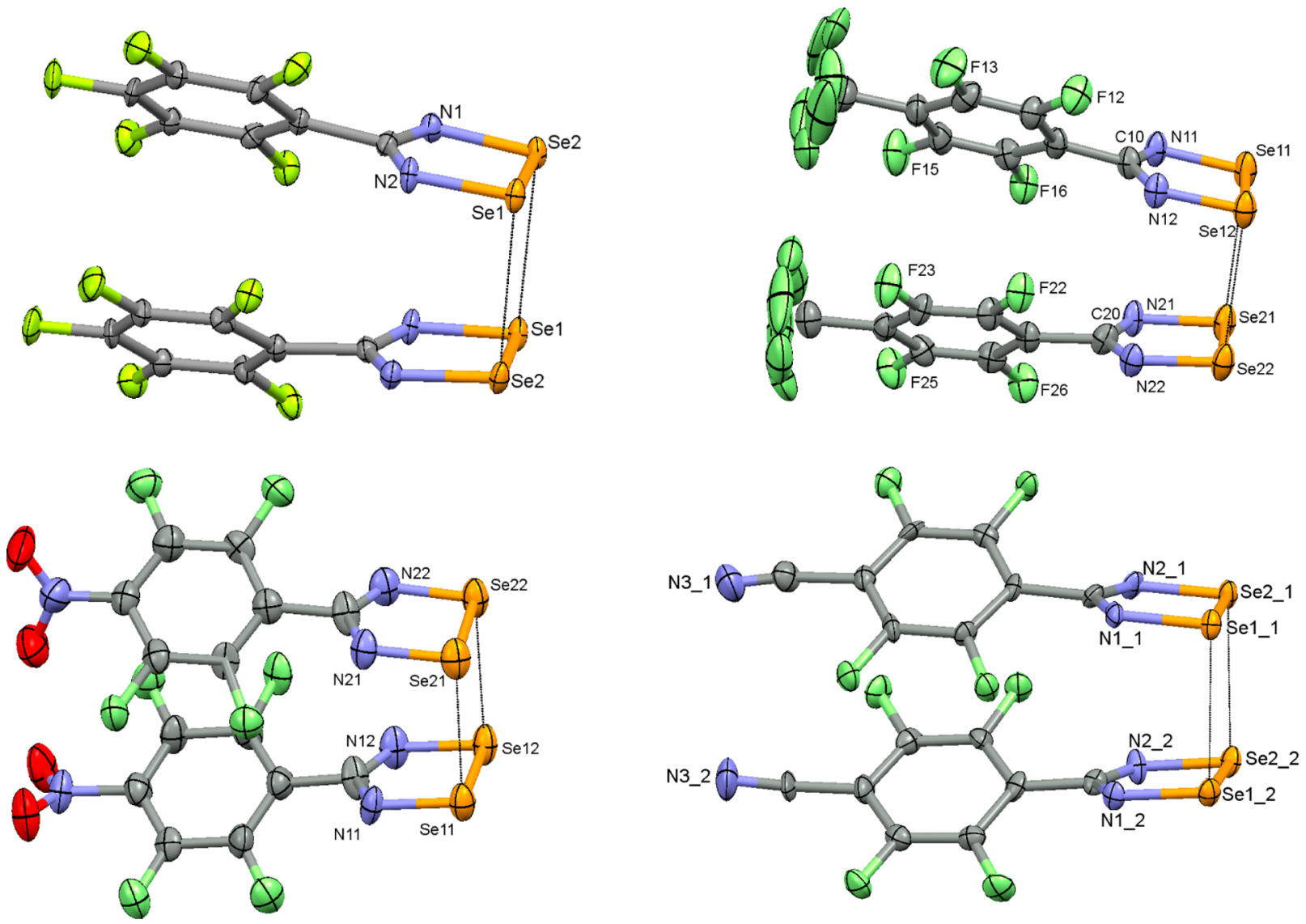

Figure 3. Cisoid dimers formed for (top) $2 \mathrm{a}$ and $2 \mathrm{~d}$ and (bottom) $2 \mathrm{e}$ and $2 \mathrm{f}$.

Both $\mathbf{2 a}$ and $\mathbf{2 d}$ are isomorphous with their DTDA analogues, ${ }^{9,30}$ but the structures of $2 \mathbf{e}$ and $2 \mathbf{f}$ adopt the cisoid dimer conformation, whereas their DTDA analogues are monomeric. However, $\mathbf{2} \mathbf{f}$ is very similar to the nonfluorinated DTDA and DSDA derivatives $p$ - $\left.\mathrm{NCC}_{6} \mathrm{H}_{4} \mathrm{CNEEN}\right)_{2}\left[Z^{\prime}=2\right.$ with a similar triclinic cell (see the $\mathrm{SI})],{ }^{14 c}$ reflecting the presence of similar structure-directing interactions in all three cases.

A more careful examination of the structures of $2 \mathbf{e}$ and $2 \mathbf{f}$ was therefore undertaken to evaluate why their DTDA congeners disfavored $\pi^{*}-\pi^{*}$ dimerization. For $2 \mathbf{f}$, the most marked component of the structure is the significant "bowing" of the molecular structure, which is observed for both molecules in 

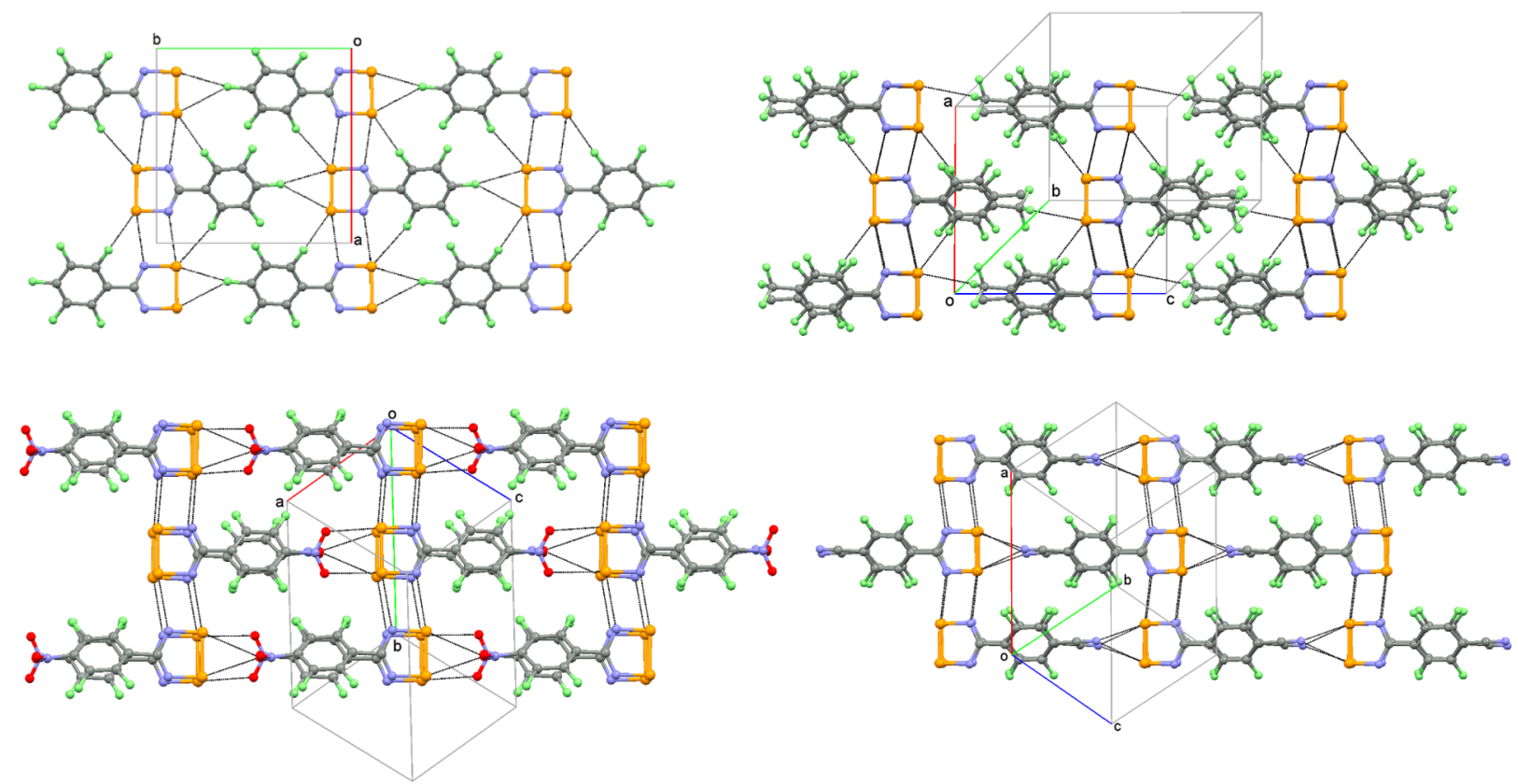

Figure 4. Cisoid dimers formed for (top) $2 a$ and $2 b$ and (bottom) $2 \mathrm{e}$ and $2 \mathrm{f}$.
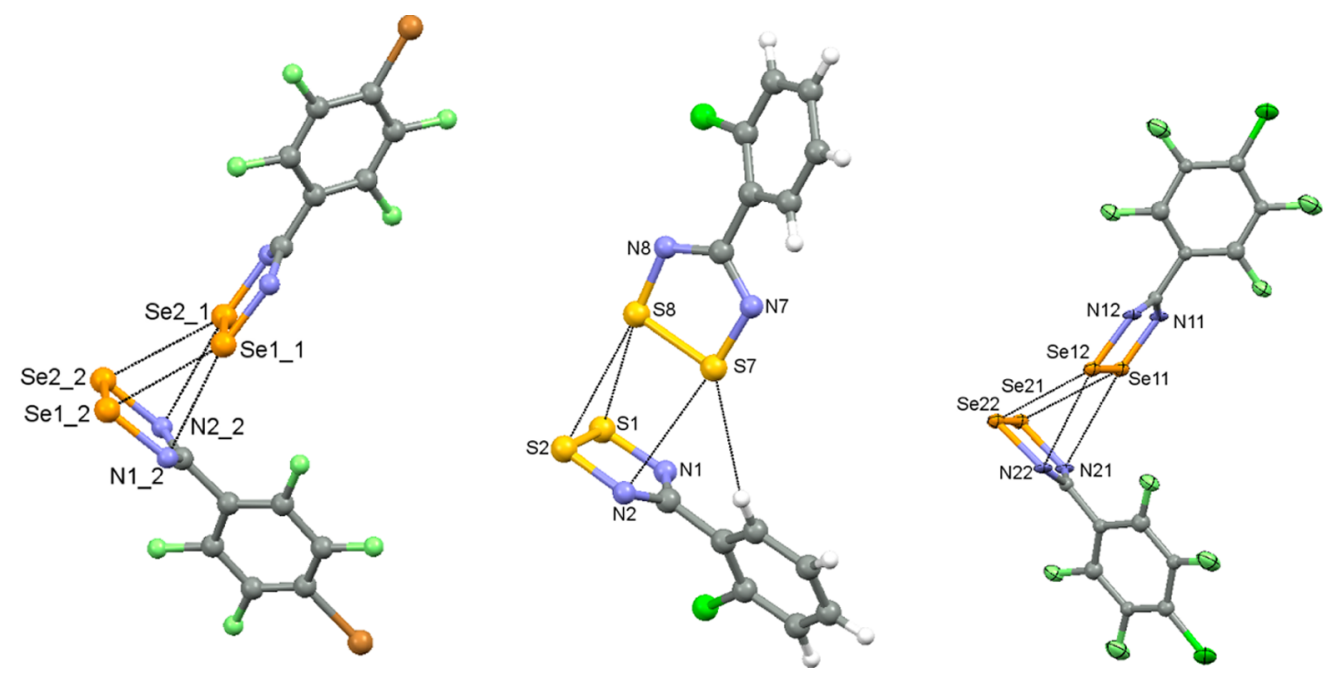

Figure 5. Molecular structures of the dimer $\mathbf{2 c}$ (left), the related orthogonal DTDA dimer $\left(o-\mathrm{ClC}_{6} \mathrm{H}_{4} \mathrm{CNSSN}\right)_{2}$ (center), and the dimer $\mathbf{2 b}$ (right).

the asymmetric unit with $\beta$ values of $175.5^{\circ}$. In addition, the $\mathrm{C}-\mathrm{C} \equiv \mathrm{N}$ bond angles $\left(172.10\right.$ and $\left.176.24^{\circ}\right)$ add further to this molecular distortion (Figure 3 ). The origin of this distortion would appear to derive from (i) the propensity for dimerization through short Se...Se intradimer contacts coupled with (ii) the thermodynamic drive to form "in-plane" CN ‥Se interactions. The inclination of the two DSeDA rings $\left(8.96^{\circ}\right)$ therefore requires significant molecular "bowing" to position the cyano groups in an appropriate position to optimize the intermolecular CN $\cdots$ Se contacts. Seemingly, both $\pi^{*}-\pi^{*}$ dimerization and $\mathrm{CN} \cdots \mathrm{S}$ motifs are structure-directing, and in $\mathbf{2 f}$, strain is built up within the molecule in order to accommodate both sets of intermolecular contacts. Conversely, in $p-\mathrm{NCC}_{6} \mathrm{~F}_{4} \mathrm{CNSSN}$, the molecular strain is released $\left(\beta=180^{\circ}\right)$ at the expense of $\pi^{*}-\pi^{*}$ dimerization, confirming that dimerization is weaker for DTDA radicals than DSeDA radicals and suggesting that the structure-directing $\mathrm{CN} \cdots \mathrm{S}$ interactions (which are retained) are stronger than the dimerization enthalpy (which is lost). In $\mathbf{2 e}$, the propensity for dimerization and formation of structuredirecting intermolecular Se...O contacts is accommodated by a build-up of strain in $\mathbf{2 e}$, with one molecule exhibiting significant bowing $\left(\beta=173.6^{\circ}\right)$, the largest $\beta$ value within this series, whereas the DTDA analogue once again releases the molecular strain $\left(\beta=180^{\circ}\right)$ at the expense of dimerization.

All four structures comprise layerlike packing motifs rather than herringbone patterns, which can be understood in terms of the electron-withdrawing nature of the $\mathrm{F}$ atoms, which depletes the $\pi$-electron density of the aryl ring. ${ }^{9}$ This reduces the strength of $\mathrm{Se}^{\delta+} \ldots \pi$ interactions, which typically favor herringbone motifs. The packing of these cisoid dimers adopt chainlike supramolecular structures that support favorable dipole-dipole interactions, and it is worth noting that all four molecules have computed dipole moments in excess of 3.4 $\mathrm{D}$ (vide infra), larger than those computed for $\mathbf{2 b}, \mathbf{2 c}$, and $2 \mathrm{~g}$.

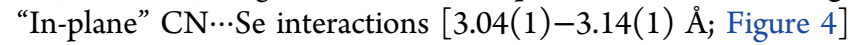
in $\mathbf{2} \mathbf{f}$ are reminiscent of the CN..S contacts in cyano- 
functionalized DTDA radicals ${ }^{6}$ and have also previously been recognized as structure-directing in cyano-functionalized DSeDA radicals. ${ }^{26 \mathrm{~b}}$ In $\mathbf{2 f}$, the close intermolecular Se $\cdots \mathrm{O}$ contacts $[2.93(2)-3.29(2) \AA]$ are comparable to the chainforming S $\cdots \mathrm{O}$ contacts in $p-\mathrm{O}_{2} \mathrm{NC}_{6} \mathrm{~F}_{4} \mathrm{CNSSN}[\mathrm{S} \cdots \mathrm{O} 3.228(2)$ $\AA]{ }^{2}$ Molecular electrostatic potential (MEPs) maps (vide infra) indicate that head-to-tail alignment is the most favorable electrostatic term for $\mathbf{2 e}$ and $\mathbf{2 f}$ but not for $\mathbf{2 a}$ and $\mathbf{2 d}$. Thus, although $\mathbf{2 a}$ and $\mathbf{2 d - 2 f}$ exhibit similar packing motifs, chain formation is most strongly favored through both dipole-dipole and electrostatic contributions in $2 \mathrm{e}$ and $\mathbf{2 f}$.

Interchain $\mathrm{Se}^{\delta+} \ldots \mathrm{N}^{\delta-}$ contacts occur between these chains in all four compounds and are reminiscent of structure-directing "SN-II interactions" described previously by Haynes et al. for the corresponding DTDA radicals. ${ }^{28}$ These contacts align neighboring chains antiparallel (Figure 4). Despite the larger van der Waals radius of the Se atom, ${ }^{29}$ the Se $\cdots \mathrm{N}$ contacts are significantly shorter $(0.15 \AA)$ than the corresponding $\mathrm{S} \cdots \mathrm{N}$ contacts (Table 4); e.g., 2a has Se $\cdots \mathrm{N}$ contacts of 3.092(6) and $3.097 \AA$, whereas the corresponding $S \cdots \mathrm{N}$ contacts in isomorphous $\left(\mathrm{C}_{6} \mathrm{~F}_{5} \mathrm{CNSSN}\right)_{2}$ are $3.249(1)$ and 3.258(1) $\AA^{9}$. This suggests that these contacts play an important and potentially more significant structure-directing role than those within the corresponding DTDA series.

Crystal Structures of $\left(p-\mathrm{ClC}_{6} \mathrm{~F}_{4} \mathrm{CNSeSeN}\right)_{2}$ (2b) and ( $p$ $\left.\mathrm{BrC}_{6} \mathrm{~F}_{4} \mathrm{CNSeSeN}\right)_{2}$ (2c). The structures of both $2 \mathbf{b}$ and $2 \mathbf{c}$ comprise unusual dimers in which the two radicals do not associate through conventional face-to-face dimer motifs but adopt an orthogonal geometry that affords a $\pi^{*}-\pi^{*}$-bonding interaction between radicals (Figure 5). Radical $\mathbf{2 b}$ crystallizes in the orthorhombic space group $P c a 2_{1}$ with two molecules in the asymmetric unit, whereas $2 \mathrm{c}$ adopts the monoclinic space group $P 2_{1} / c$ but also with two molecules in the asymmetric unit. The twist angles between DSeDA and the phenylene ring planes (Table 2) in these orthogonal dimers $\left(56.34-59.70^{\circ}\right)$ are much larger than those in the cisoid dimers $\left(34.65-42.03^{\circ}\right)$ and closer to the energy minimum (ca. $50^{\circ}$ ). The bowing parameters $(\beta)$ in these two structures deviate by less than $3^{\circ}$ from the idealized $180^{\circ}$. Both the $\theta$ and $\beta$ parameters therefore suggest the release of molecular strain with respect to the cisoid dimers $\mathbf{2 a}$ and $\mathbf{2} \mathbf{d}-\mathbf{2} \mathbf{f}$ such that any potential weakening of the $\pi^{*}-\pi^{*}$ dimerization accompanied by a change from cisoid to orthogonal dimerization mode is offset by the release of strain. The "orthogonal" $\pi^{*}-\pi^{*}$ interaction in $\mathbf{2 b}$ has the two DSeDA rings inclined at $81.51^{\circ}$, whereas for $2 \mathrm{c}$, the angle is $84.36^{\circ}$. The intradimer Se $\cdots \mathrm{Se}[3.110(7)-3.207(7) \AA]$ and $\mathrm{Se} \cdots \mathrm{N}$ $[3.04(3)-3.11(3) \AA]$ contacts within these dimers provide a sufficiently close approach to quenching the radical paramagnetism (vide infra). Such behavior is not entirely without precedent, and in DTDA chemistry, one of the two crystallographically independent dimers within the structure of $\left(o-\mathrm{ClC}_{6} \mathrm{H}_{4} \mathrm{CNSSN}\right)_{2}$ adopts a similar "orthogonal" $\pi^{*}-\pi^{*}$ interaction (Figure $5 \mathrm{~b}$ ), although the relative orientations of the two rings are different. ${ }^{31}$

The packing motifs of $\mathbf{2 b}$ and $\mathbf{2 c}$ are similar to those of orthogonal dimers linked together via additional interdimer $\mathrm{Se} \cdots \mathrm{N}$ contacts $[3.02(2)-3.25(3) \AA \AA$; Figure 6] to form supramolecular chains. These interdimer contacts are similar to the bifurcated SN-I contacts previously identified in DTDA chemistry. Again it is worth noting that the dimeric structure of $2 \mathrm{c}$ is in contrast to the monomeric $p-\mathrm{BrC}_{6} \mathrm{~F}_{4} \mathrm{CNSSN},{ }^{17 \mathrm{a}}$ yet in both cases, the electronegative $\mathrm{N}$ atom appears to favor contacts to soft, polarizable elements. In $\mathbf{2 c}$, the orthogonal
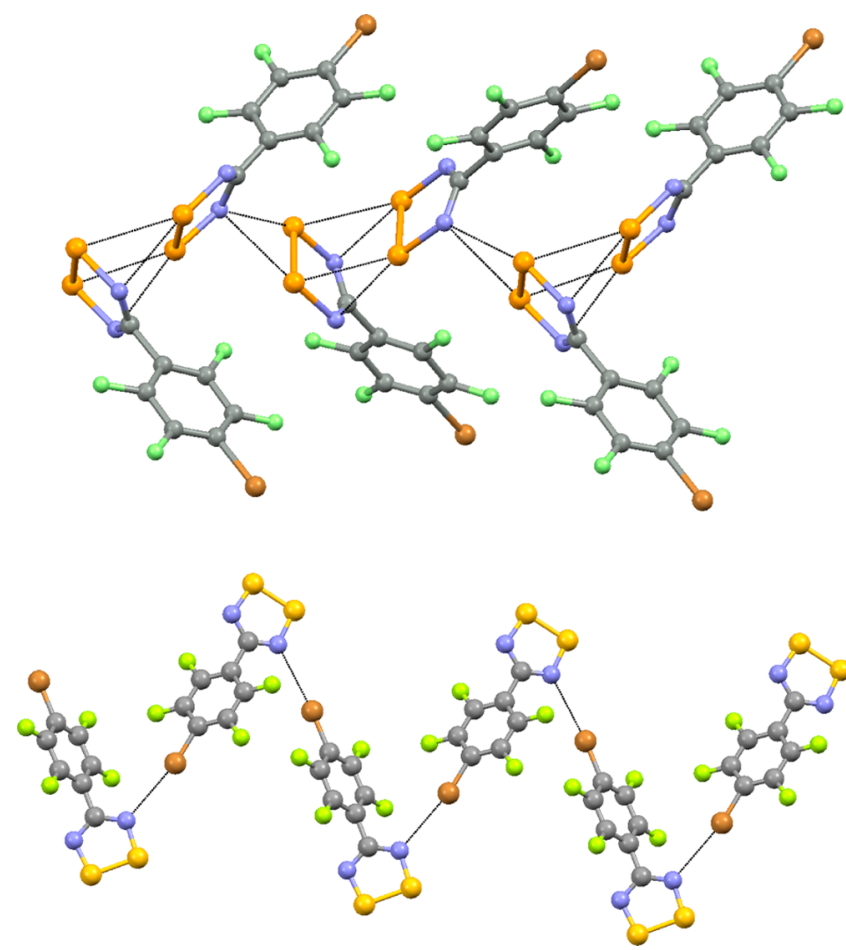

Figure 6. Chainlike motif generated through bifurcated $\mathrm{Se} \cdots \mathrm{N}$ contacts between orthogonal dimers in $2 \mathrm{c}$ (top) and chainlike motif generated through $\mathrm{Br} \cdots \mathrm{N}$ contacts within $p-\mathrm{BrC}_{6} \mathrm{~F}_{4} \mathrm{CNSSN}$ (bottom).

dimer exhibits close intermolecular bifurcated $\mathrm{N}$...Se contacts, whereas for $p-\mathrm{BrC}_{6} \mathrm{~F}_{4} \mathrm{CNSSN}$, the heterocyclic $\mathrm{N}$ atom forms close intermolecular $\mathrm{N} \cdots \mathrm{Br}$ contacts (cf. the electronegativities of the Se and $\mathrm{Br}$ atoms at 2.55 and 2.96, respectively).

Crystal Structure of $\left[2,4,6-\left(\mathrm{F}_{3} \mathrm{C}_{3} \mathrm{C}_{6} \mathrm{H}_{2} \mathrm{CNSeSeN}\right]_{2}\right.$ (2g). In a "final" attempt to suppress dimerization, the $\mathrm{RC}_{6} \mathrm{~F}_{4}$ substituent was replaced by the sterically demanding perfluoromesityl group 2,4,6-( $\left(\mathrm{F}_{3} \mathrm{C}\right)_{3} \mathrm{C}_{6} \mathrm{H}_{2}$. This group has been shown to inhibit dimerization in DTDA radicals, although $\left(\mathrm{F}_{3} \mathrm{C}\right)_{3} \mathrm{C}_{6} \mathrm{H}_{2} \mathrm{CNSSN}$ has been found to be polymorphic, with one phase comprising just DTDA radical monomers and the other phase exhibiting a mixture of both monomers and trans-antarafacial dimers [S...S $=3.443(2) \AA] .{ }^{17 \mathrm{c}}$ Despite the long intradimer S $\cdots S$ separation, SQUID magnetic measurements indicated that below $275 \mathrm{~K}$ the trans-antarafacial dimer did not contribute to sample paramagnetism. Radical $\mathbf{2 g}$ crystallizes in the triclinic space group $P \overline{1}$ with three molecules in the asymmetric unit, comprising one and a half trans-antarafacial dimers, with the one dimer in a general position and the second dimer located about the crystallographic inversion center associated with the $P \overline{1}$ space group. The presence of the two $\mathrm{CF}_{3}$ groups in the 2 and 6 positions leads to significantly larger twist angles between the aryl and DSeDA ring planes $\left(75.83-89.70^{\circ}\right)$, and the $\beta$ values (Table 2) reflect negligible geometric strain. The intradimer Se $\cdots$ Se distances of $3.230(2)-3.334(2) \AA$ are markedly shorter than those observed for the sulfur analogue, reflecting a singlet ground state, and closer to the other transantarafacial diamagnetic DTDA $\pi^{*}-\pi^{*}$ dimer [m$\left.\left.\mathrm{NCC}_{6} \mathrm{H}_{4} \mathrm{CNSSN}\right)_{2} ; 3.1413(8) \AA\right] .{ }^{14 \mathrm{c}}$ These trans-antarafacial dimers are linked via interdimer Se $\cdots \mathrm{N}$ contacts (Figure 7 ), which fall in the range $2.840(9)-3.288(9) \AA$, and comprise both SN-II- and SN-III-like contacts in relation to the established close contacts in DTDA chemistry. ${ }^{17}$ 

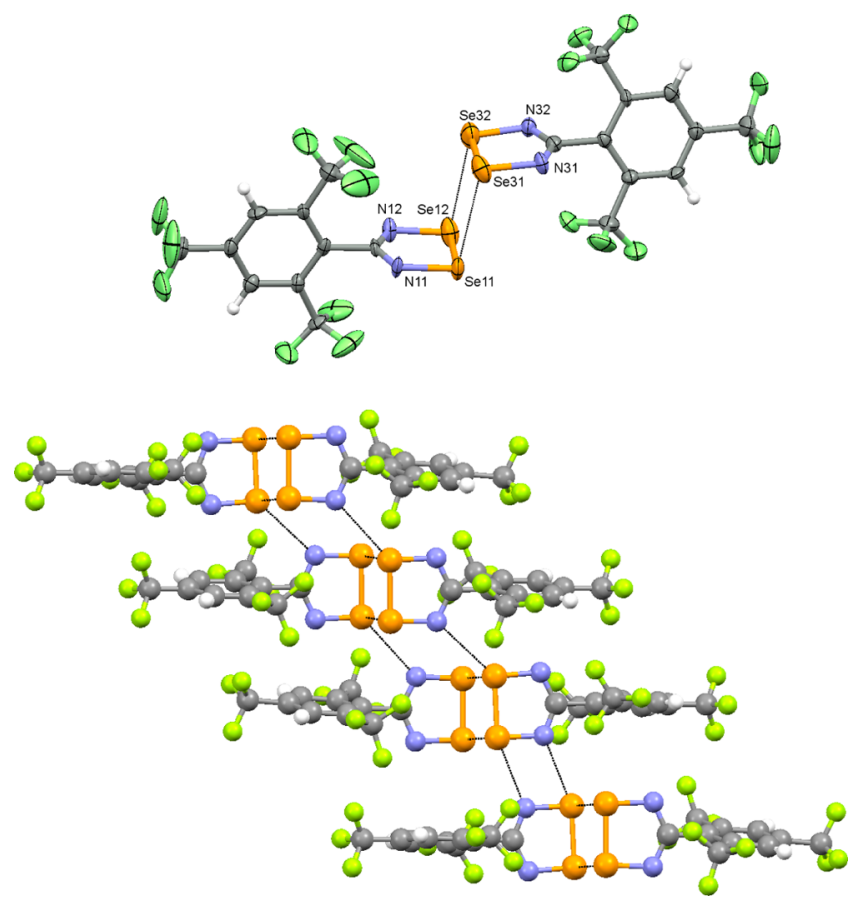

Figure 7. Molecular structure of one of the trans-antarafacial dimers of $\mathbf{2 g}$ (top) and solid-state packing of $\mathbf{2 g}$ (bottom), illustrating interdimer Se $\cdots \mathrm{N}$ contacts.

Magnetic Studies. The Se $\cdots$ Se contacts within the cisoid dimers $\mathbf{2 a}$ and $\mathbf{2} \mathbf{d} \mathbf{- 2} \mathbf{f}$ as well as the trans-antarafacial dimer $\mathbf{2 g}$ are systematically $0.1-0.2 \AA$ longer than those of the cisoid and trans-antarafacial DTDA dimers. The increased spin density at selenium and larger radial distribution function, which favors strong dimerization, did not merit SQUID magnetic measurements on these derivatives. In contrast, the unique orthogonal dimerization associated with $\mathbf{2 b}$ and $\mathbf{2 c}$ prompted us to probe their magnetic behavior through SQUID magnetometry. Variable-temperature measurements were made on $\mathbf{2 b}$ and $\mathbf{2 c}$ from 1.8 to $300 \mathrm{~K}$ in an applied field of $1 \mathrm{~T}$. Additional $M$ versus $H$ measurements were undertaken at 1.8 and $3.0 \mathrm{~K}$ for both $2 \mathbf{b}$ and $2 \mathbf{c}$ in fields of up to $5 \mathrm{~T}$. An additional $M$ versus $H$ plot was recorded for $2 \mathrm{c}$ at $300 \mathrm{~K}$. Both samples were found to be weakly paramagnetic, consistent with singlet dimer configurations and a small number of lattice defects $(0.5 \%$ monomer with a Weiss constant of $-0.6 \mathrm{~K}$ in both cases; see the SI). Unlike selected DTDA dimers that exhibit a small increase in paramagnetism upon warming, $\mathbf{2 b}$ and $\mathbf{2 c}$ showed no evidence for an increase in susceptibility up to $300 \mathrm{~K}$, consistent with a well-isolated singlet ground state.

Computational Studies. Previous computational studies on the parent diselenadiazolyl, $\mathrm{HCNSeSeN}$, revealed that valence minimal basis sets were unable to reproduce accurately the molecular geometry, but basis sets implementing effective core potentials supplemented by additional polarization functions were better able to reproduce the bonding within and between diselenadiazolyl radicals. ${ }^{32}$ More recent computational studies on the dimerization within $(\mathrm{HCNEEN})_{2}(\mathrm{E}=\mathrm{S}$, $\mathrm{Se}$ ) have shown that successful reproduction of the geometry of these pancake dimers is sensitive to the functional employed; ${ }^{12}$ Kertesz et al. identified that some functionals underestimated the intradimer separation, whereas others overestimated this parameter or failed entirely to identify a minimum on the potential energy surface for the weakly bound $\pi^{*}-\pi^{*}$ dimer.
The common functional B3LYP, for example, failed to identify the $\pi^{*}-\pi^{*}$ dimer as a minimum on the potential energy surface. ${ }^{12}$ Their calculations suggested unrestricted M06, BP86, and B97-D3, and the M06-D3 functional appeared to be best suited to reproduce the molecular geometry of the $(\mathrm{HCNSeSeN})_{2}$ dimer, successfully locating energy minima in the vicinity of the experimental value. In addition, they examined the convergence of the basis set and found a reasonable energy convergence with a polarized triple- $\zeta$ basis set augmented with diffuse functions $[6-311++G(d, p)]$.

We re-examined the M06 functional, which is well-suited for thermodynamic calculations on main-group compounds, ${ }^{33}$ along with the PBE0 functional, which reproduces well weak intermolecular forces. ${ }^{33}$ All calculations additionally employed Grimme's D3 a posteriori correction for dispersion forces that are not implicitly computed in DFT and that are likely significant for such weak intermolecular interactions. ${ }^{35}$ In order to improve the computational efficiency for larger structures, we also examined a series of basis sets with effective core potentials in order to reduce the computational burden. Among those we examined, we found that the cc-PVTZ-PP $(-F)++$ basis set provided very good agreement with the "all-electron" 6$311++\mathrm{G}(\mathrm{d}, \mathrm{p})$ used previously, ${ }^{12}$ in terms of both the computed geometry and dimerization energy for cisoid $(\mathrm{HCNSeSeN})_{2}$.

A subsequent comparison of the M06-D3 and PBE0-D3 functionals (Table 3) led to an excellent reproduction of the

Table 3. Experimental and Computed Distances within the Cisoid Dimer (HCNSeSeN $)_{2}$ Using UM06-D3 and PBE0-D3 Functionals $^{a}$

\begin{tabular}{lcccc} 
& & \multicolumn{3}{c}{ computed } \\
\cline { 3 - 5 } & exptl & $\begin{array}{c}\text { UM06-D3 } \\
\text { 311++G(d,p) }\end{array}$ & $\begin{array}{c}\text { UM06-D3 cc- } \\
\text { PVTZ-PP(-F)++ }\end{array}$ & $\begin{array}{c}\text { PBE0-D3 cc- } \\
\text { PVTZ-PP(-F)++ }\end{array}$ \\
Se-Se & 2.33 & 2.35 & 2.36 & 2.35 \\
$\mathrm{Se}-\mathrm{N}$ & 1.80 & 1.77 & 1.78 & 1.79 \\
$\mathrm{~N}-\mathrm{C}$ & 1.33 & 1.33 & 1.32 & 1.32 \\
$\mathrm{Se} \cdots \mathrm{Se}$ & 3.26 & 3.14 & 3.29 & 3.21 \\
$\mathrm{~N} \cdots \mathrm{N}$ & 3.27 & 3.18 & 3.25 & 3.27 \\
$\mathrm{C} \cdots \mathrm{C}$ & 3.31 & 3.20 & 3.25 & 3.29 \\
$\mathrm{D}_{\mathrm{e}} /(\mathrm{kJ}$ & & 15 & 17 & 21 \\
$\left.\mathrm{~mol}^{-1}\right)$ & & & &
\end{tabular}

${ }^{a_{T}}$ The dissociation energy $D_{\mathrm{e}}$ is the energy change $E_{\text {dimer }} \rightarrow 2 E_{\text {monomer }}$.

dimer geometry and a slight increase in the dissociation energy $\left(21 \mathrm{~kJ} \mathrm{~mol}^{-1}\right)$. At the same level of theory, the dissociation energy of $(\mathrm{HCNSSN})_{2}$ was computed to be $7 \mathrm{~kJ} \mathrm{~mol}^{-1}$, indicating that the $(\mathrm{HCNSeSeN})_{2}$ dimer is significantly more stable than ( $\mathrm{HCNSSN})_{2}$. Although there is no experimental data on the stability of $(\mathrm{HCNSSN})_{2}$ itself, the dimerization enthalpies for several DTDA radicals have been measured in solution, e.g., $\left.(\mathrm{PhCNSSN})_{2}\left(-37 \mathrm{~kJ} \mathrm{~mol}^{-1}\right), \mathrm{F}_{3} \mathrm{CCNSSN}\right)_{2}$ $\left(-37 \mathrm{~kJ} \mathrm{~mol}^{-1}\right), \quad\left({ }^{\mathrm{t}} \mathrm{BuCNSSN}\right)_{2}\left(-31 \mathrm{~kJ} \mathrm{~mol}^{-1}\right)$, and $(\text { pyCNSSN })_{2}\left(-35 \mathrm{~kJ} \mathrm{~mol}^{-1}\right){ }^{23,24}$ Magnetic measurements on a number of weakly dimerized DTDA radicals ${ }^{10,11}$ have shown the onset of paramagnetism at elevated temperatures from which estimated solid-state dimerization energies in the region of -8 to $-11 \mathrm{~kJ} \mathrm{~mol}^{-1}$ were determined. It is unsurprising that solution and solid-state dimerization enthalpies differ due to variation between the intermolecular forces in the solid-state and solvation effects in solution state. These experimental data are ca. 1-5 times greater than the computed gas-phase value for $(\mathrm{HCNSSN})_{2}$, placing the 
corresponding solution dimerization enthalpy for DSeDA radicals in the $20-100 \mathrm{~kJ} \mathrm{~mol}^{-1}$ region. Although there is considerable uncertainty in this value, there is no doubt that the experimental and computational data both point to DSeDA radicals exhibiting stronger dimerization enthalpies than the corresponding DTDA radicals.

Dimerization Energy. In order to assess the relative stabilities of the different modes of association for DSeDA dimers, geometry optimizations for $(\mathrm{HCNSeSeN})_{2}$ were undertaken for the cis-cofacial dimer, the trans-antarafacial mode of association, and the orthogonal interaction. The optimized geometries are in very good agreement with those determined experimentally. In general, these computations slightly underestimate the closest intradimer contacts, but the agreement overall is remarkably good, with the largest deviation from the experimental data being the Se...Se contact within the trans-antarafacial mode ( $5 \%$ error). The computed dissociation energies indicate that the dimer stability is in the order ciscofacial $>$ orthogonal $>$ trans-antarafacial (Table 4).

Table 4. Experimental and Computed [PBE0-D3/cc-PVTZPP(-F)++] Distances within the Dimer $(\mathrm{HCNSeSeN})_{2}$ for Cis-Cofacial, Trans-Antarafacial, and Orthogonal Conformations $^{a}$

\begin{tabular}{|c|c|c|c|c|c|c|}
\hline & \multicolumn{2}{|c|}{ cis-cofacial } & \multicolumn{2}{|c|}{ trans-antarafacial } & \multicolumn{2}{|c|}{ orthogonal } \\
\hline & exptl & calcd & exptl & calcd & exptl & calcd \\
\hline $\mathrm{Se}-\mathrm{Se}$ & 2.33 & 2.35 & 2.29 & 2.34 & 2.35 & 2.36 \\
\hline $\mathrm{Se}-\mathrm{N}$ & 1.80 & 1.79 & 1.78 & 1.79 & 1.80 & 1.79 \\
\hline $\mathrm{N}-\mathrm{C}$ & 1.33 & 1.32 & 1.32 & 1.32 & 1.33 & 1.32 \\
\hline $\mathrm{Se} \cdots \mathrm{Se}$ & 3.26 & 3.21 & 3.29 & 3.16 & 3.16 & 3.10 \\
\hline $\mathrm{Se} \cdots \mathrm{N}$ & & & & & 3.06 & 2.96 \\
\hline $\mathrm{N} \cdots \mathrm{N}$ & 3.27 & 3.27 & 5.25 & 5.20 & 4.85 & 4.75 \\
\hline $\mathrm{C} \cdots \mathrm{C}$ & 3.31 & 3.29 & 6.14 & 6.22 & 5.63 & 5.50 \\
\hline $\mathrm{D}_{\mathrm{e}} / \mathrm{kJ} \mathrm{mol}^{-1}$ & & 21 & & 16 & & 19 \\
\hline
\end{tabular}

${ }^{a}$ The geometric parameters for trans-antarafacial and orthogonal conformations are averages of those observed experimentally for $(\mathrm{RCNSeSeN})_{2}$ dimers.

Previous studies have shown that solid-state molecular geometries cluster near computed energy minima, such that with a statistically significant quantity of data clear correlations exist between the distribution of observed conformations and the energy profile. ${ }^{36}$ Although the number of DSeDA structures is hardly large for statistical purposes, the computed energies of the different dimerization modes appear to fit well with the experimental observations. A search of the CSD, coupled with the current studies, provides a total of 22 structures for pristine DSeDA radicals, of which 17 (77\%) adopt the cisoid conformation and 2 (9\%) adopt the orthogonal interaction. Just one example of each of the trans-antarafacial, twisted, ${ }^{37}$ and trans-cofacial $^{38}$ dimerization modes (5\% each) make up the remainder. Even taking into account the fact that the computed dissociation energies underestimate the experimental data, the modest computed differences between different dimerization modes suggest that other packing forces (dispersion, dipoledipole, and electrostatic interactions) likely play a significant role in determining the structural outcome of the dimerization process. In order to probe the nature of the intermolecular interactions in derivatives of $\mathbf{2}$, in relation to the dimerization energy, we undertook further computations to probe the different contributions to the intermolecular forces.
Dipole-Dipole Interactions. The computed molecular dipoles for radicals $\mathbf{2 a - 2} \mathbf{g}$ are presented in Table 5. In order

Table 5. Computed [Unrestricted PBE0-D3 cc-PVTZ-PP(F)++] Dipole Moments for Radicals 2a-2g

\begin{tabular}{cccccccc} 
& $\mathbf{2 a}$ & $\mathbf{2 b}$ & $\mathbf{2 c}$ & $\mathbf{2 d}$ & $\mathbf{2 e}$ & $\mathbf{2 f}$ & $\mathbf{2 g}$ \\
dipole/D & 3.46 & 4.69 & 2.96 & 3.18 & 6.71 & 6.20 & 2.61 \\
\hline
\end{tabular}

to validate these values, we also calculated the dipoles for thiophene $(0.54 \mathrm{D})$ and water $(1.86 \mathrm{D})$ using the same methodology, which were found to be in excellent agreement with experiment. ${ }^{39}$ It is clear from these data that all radicals in this series exhibit a strong molecular dipole, although the magnitude of the dipole is strongly correlated with the substituent $\mathrm{X}$. At the lower end of the spectrum, $2 \mathrm{c}(\mathrm{X}=\mathrm{Br})$ and $2 \mathrm{~d}(\mathrm{X}=\mathrm{Cl})$ exhibit dipole moments of around 2.5-3.1 D, whereas $2 \mathrm{e}(\mathrm{X}=\mathrm{CN})$ and $2 \mathrm{f}\left(\mathrm{X}=\mathrm{NO}_{2}\right)$ exhibit dipoles in excess of $6 \mathrm{D}$. It is worth noting that those radicals with a smaller dipole (2c, 2d, and $\mathbf{2 g}$ ) do not adopt chain motifs, whereas those with larger dipoles all adopt chainlike structures. When using a point dipole approximation (eq 1), ${ }^{40}$ we find that the large intermolecular distances between centroids along the chain direction give rise to energetically small dipole-dipole interactions. For example, the cyano derivative $2 \mathrm{e}$ has the largest molecular dipole $(6.71 \mathrm{D})$, but the large separation of radicals along the chain direction $(12.11 \AA$ ) using a point dipole approximation (eq 1) affords a dipole-dipole interaction of ca. $3 \mathrm{~kJ} \mathrm{~mol}^{-1}$. While this is energetically small in relation to the calculated dimerization energy, it is comparable in relation to the difference in energies between possible dimerization modes.

$$
V=\left(\mu_{1} \mu_{2} / 4 \pi \varepsilon_{0}\right)\left(1 / d^{3}\right)\left(1-3 \cos ^{2} \theta\right)
$$

Coulombic Interactions. Electrostatic interactions between DTDA radicals have previously been exploited to account for the possible packing motifs in simple DTDA radicals such as (HCNSSN $)_{2}$ and $(\mathrm{ClCNSSN})_{2}{ }^{28}$ The MEPs for $\mathbf{2 a - 2 f}$, mapped onto their total electron density surface, are presented in Figure 8. All MEPs reveal regions of positive charge (deep blue) in the vicinity of the Se atoms as the most electropositive area. However, the most electronegative region (red) varies considerably. In $\mathbf{2 a}$ and $\mathbf{2 d}$, it is clear that the region of largest

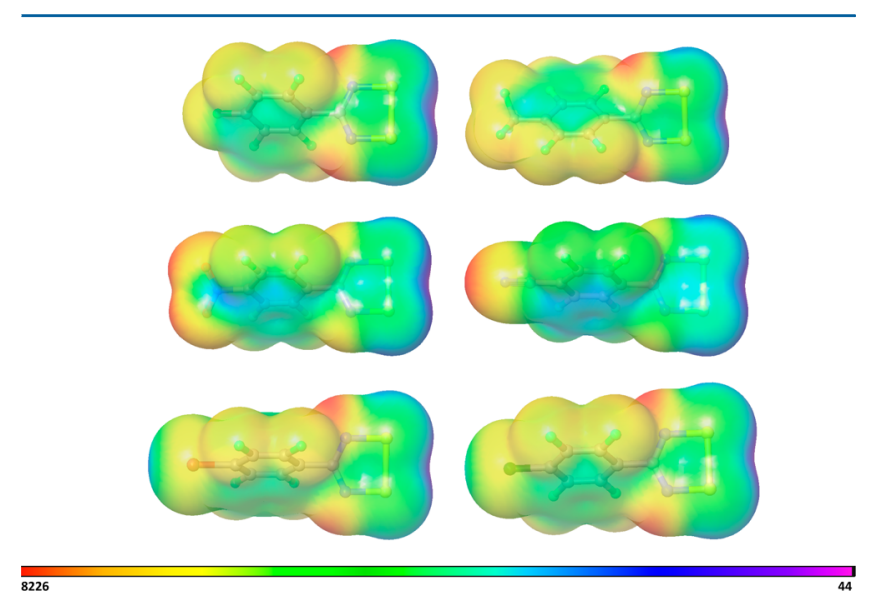

Figure 8. MEPs (atomic units) plotted on the electron density surface for (top) $\mathbf{2 a}$ and $\mathbf{2 d}$, (center) $\mathbf{2 e}$ and $\mathbf{2 f}$, and (bottom) $\mathbf{2 b}$ and $\mathbf{2 c}$. Red represents regions of greatest partial negative charge, and blue-purple represents the largest partial positive charge. 
partial negative charge is associated with the heterocyclic $\mathrm{N}$ atoms, and thus the most favorable electrostatic interaction is likely to be $\mathrm{Se}^{\delta+} \ldots \mathrm{N}^{\delta-}$. This is manifested in the short lateral contacts perpendicular to the molecular chains [2.941(7)$3.097(6) \AA]$ for $2 \mathrm{a}$ and $2 \mathrm{~d}$. Although the structures of $2 \mathrm{e}$ and $2 \mathrm{f}$ appear superficially similar to $\mathbf{2 a}$ and $\mathbf{2 d}$, the largest partial charge on the electron density surface now occurs at the cyano and nitro substituents, with a corresponding diminution of negative charge in the vicinity of the heterocyclic $\mathrm{N}$ atoms. The strongest electrostatic interaction in these cases would therefore appear to be the $\mathrm{Se}^{\delta+} \ldots{ }^{\delta-} \mathrm{NC}$ and $\mathrm{Se}^{\delta+} \ldots \mathrm{O}^{\delta-}$ interactions, which generate the experimentally observed molecular chains. The interchain lateral Se $\cdots \mathrm{N}$ contacts $[3.06(3)-3.26(3) \AA]$, while superficially similar to those for $\mathbf{2 a}$ and $\mathbf{2 d}$, tend to be a little longer on average, presumably as a consequence of the reduction in the partial negative charge at the heterocyclic $\mathrm{N}$ atoms. For $\mathbf{2 b}$ and $\mathbf{2 c}$, the halogen substituents are the most electropositive (green-blue) in the series, and thus the chainforming $\mathrm{Se} \cdots \mathrm{X}(\mathrm{X}=\mathrm{Cl}, \mathrm{Br})$ interaction is electrostatically unfavorable in relation to $\mathrm{N} \cdots \mathrm{X}$ contacts.

Dispersion. The contribution to dispersion was estimated using the difference in energy between single-point calculations on two molecules of $2 \mathrm{f}$ linked via $\mathrm{CN}$...Se interactions (extracted from the solid-state structure) and a single-point calculation on the crystallographically determined geometry of 2f. The total computed dissociation energy to break the $\mathrm{CN}$... Se interaction was $26 \mathrm{~kJ} \mathrm{~mol}^{-1}$, of which the dispersion (D3) contribution was $5 \mathrm{~kJ} \mathrm{~mol}{ }^{-1}$.

\section{DISCUSSION}

These computational studies indicate that the dimerization energy of DSeDA radicals is ca. 3 times higher than that observed for DTDA radicals, with the cisoid, trans-antarafacial, and orthogonal dimers all appearing as stable entities on the potential energy surface. The cis geometry is most stable and in good agreement with the experimentally determined preference for cisoid solid-state structures. Disruption of this substantial propensity for $\pi^{*}-\pi^{*}$ dimerization relies on a series of other competitive noncovalent interactions, which can successfully outcompete the dimerization energy. To date, this has not been achieved in DSeDA chemistry, whereas a number of DTDA radicals do retain their paramagnetism in the solid state. In many cases, the DSeDA and DTDA radicals appear to be isostructural, so the DSeDA analogues of monomeric DTDA radicals provide useful structural comparisons as "hypothetical" dimer conformations. In order to probe these intermolecular interactions, we selected $2 \mathrm{f}$ for further study because both the $\mathrm{CN} \cdots \mathrm{S}$ and $\mathrm{CN} \cdots \mathrm{Se}$ interactions appear as well-established supramolecular synthons. At the PBE0-D3 cc-PVTZ-PP(-F)++ level of theory, the total energy associated with each $\mathrm{CN}$...Se interaction is ca. $26 \mathrm{~kJ} \mathrm{~mol}^{-1}$. With each molecule forming two such interactions $\left(52 \mathrm{~kJ} \mathrm{~mol}^{-1}\right)$, there is a considerable structural driving force for chain formation. In the DTDA derivative $p-\mathrm{NCC}_{6} \mathrm{~F}_{4} \mathrm{CNSSN}$, dimerization is sacrificed in order to optimize the $\mathrm{CN} \cdots \mathrm{S}$ contacts, whereas in $\mathbf{2 f}$, the greater dimerization energy inhibits monomer formation, albeit at the expense of some molecular strain. A comparison of the energy of the crystallographically determined structure of $\mathbf{2 f}$ (strained) with its geometry-optimized (unstrained) structure reveals a remarkably large strain energy of ca. $85 \mathrm{~kJ} \mathrm{~mol}^{-1}$ ! Therefore, the driving force for dimerization in $\mathbf{2 f}$ must be clearly substantial, whereas in the lighter sulfur analogue, the strain required to adopt a related cisoid dimer conformation is clearly too great and dimerization is sacrificed with the release of strain.

\section{CONCLUSION}

A number of novel diselenadiazolyls have been prepared and structurally characterized. Four of these derivatives $\left(\mathrm{X}=\mathrm{F}, \mathrm{CF}_{3}\right.$, $\mathrm{NO}_{2}, \mathrm{CN}$ ) form cisoid dimers, whereas for $\mathrm{X}=\mathrm{Cl}$ and $\mathrm{Br}$, an unusual orthogonal dimer interaction is adopted. The use of $\mathrm{CF}_{3}$ groups in the 2 and 6 positions disrupts the preferred cisoid dimer conformation, affording the first example of a trans-antarafacial DSeDA dimer. Computational studies reveal that each of these dimers is a minimum on the potential energy surface, and for the prototypal $(\mathrm{HCNSeSeN})_{2}$, the order of stability is cisoid $>$ orthogonal $>$ trans-antarfacial, which is in agreement with the observed distribution of structures within the CSD and this current dataset. The propensity for many DTDA and DSeDA radicals to adopt isomorphous structures means that these DSeDA dimers provide valuable alternative hypothetical "dimer structures" for established monomeric DTDA radicals. The observation of dimerization throughout the series $\mathbf{2 a}-\mathbf{2 g}$ coupled with computational studies reflects stronger dimerization energies for DSeDA radicals in relation to DTDA radicals. This is manifested in significant molecular distortions in the cases of $\mathbf{2 e}$ and $\mathbf{2} \mathbf{f}$ (whose sulfur analogues do not exhibit dimer structures) to accommodate the combination of both favorable dimerization and supramolecular chainforming interactions. In the DTDA derivatives, dimerization is not observed, but $\mathrm{CN} \cdots \mathrm{S}$ contacts are retained, suggesting that the molecular strain is greater than the dimerization energy gained. A comparison of the strain energy (computed for the selenium analogue $\mathbf{2 f}$ ) in relation to the typical dimerization energy in solution for DTDA radicals $\left(35 \mathrm{~kJ} \mathrm{~mol}^{-1}\right)$ is at least qualitatively consistent with this perspective.

\section{EXPERIMENTAL SECTION}

General Considerations. All reactions and manipulations were carried out under an atmosphere of dry, oxygen-free nitrogen using standard double-manifold techniques with a rotary oil pump. A nitrogen-filled glovebox (Saffron Scientific $\beta$-range) was used to manipulate solids including storage of starting materials, room temperature reactions, product recovery, and sample preparation for analysis. Molecular sieves $(4 \AA)$ were dried at $120^{\circ} \mathrm{C}$ for $24 \mathrm{~h}$ prior to use. All solvents (diethyl ether, MeCN toluene, and THF) were dried before use and stored over molecular sieves under a nitrogen atmosphere. Deuterated solvents were dried over molecular sieves before use. Chemicals were purchased from commercial suppliers and used as received or prepared according to the literature methods. ${ }^{41}$ $\mathrm{SeCl}_{2}$ was prepared in situ and used directly by the following method: gray selenium and $\mathrm{SeCl}_{4}$ were mixed together in a $1: 1$ ratio in a Schlenk tube without solvent to give $\mathrm{SeCl}_{2}$ as a dark viscous red-black liquid. An Exeter CE-440 elemental analyzer was used for carbon, hydrogen, and nitrogen elemental analyses. IR spectra were prepared as a Nujol mulls between $\mathrm{NaCl}$ plates and recorded on a PerkinElmer Paragon 1000 FT-IR spectrometer. Unit mass spectrometry was performed in positive-ion electron impact mode on a Kratos MS890EI mass spectrometer.

Synthesis of 2a. Pentafluorobenzonitrile $(0.4 \mathrm{~mL}, 610 \mathrm{mg}, 3.16$ $\mathrm{mmol})$ was added to a solution of $\mathrm{LiN}\left(\mathrm{SiMe}_{3}\right)_{2}(528 \mathrm{mg}, 3.16 \mathrm{mmol})$ in $\mathrm{Et}_{2} \mathrm{O}(20 \mathrm{~mL})$ and the solution stirred at room temperature for 16 h. The solution was added via cannula to freshly prepared $\mathrm{SeCl}_{2}(3.17$ $\mathrm{mmol})$ at $0{ }^{\circ} \mathrm{C}$. The reaction mixture was allowed to warm to room temperature and stirred for $4 \mathrm{~h}$. The brown precipitate was filtered, washed with $\mathrm{Et}_{2} \mathrm{O}(3 \times 20 \mathrm{~mL})$, and dried in vacuo. $\mathrm{Ph}_{3} \mathrm{Sb}(882 \mathrm{mg}$, $2.5 \mathrm{mmol}$ ) was added to the crude chloride salt followed by $\mathrm{MeCN}$ $(20 \mathrm{~mL})$. The reaction mixture was heated to reflux for $5 \mathrm{~h}$ and then allowed to cool to room temperature. The solvent was removed in 
vacuo and the solid residue purified by sublimation $\left(110^{\circ} \mathrm{C}, \sim 10^{-2}\right.$ Torr) with 2 a collected on a water-cooled coldfinger (323 mg, $28 \%$, $0.88 \mathrm{mmol}$ ). Elem anal. Calcd for $\mathrm{C}_{7} \mathrm{~F}_{5} \mathrm{~N}_{2} \mathrm{Se}_{2}: \mathrm{C}, 23.03 ; \mathrm{H}, 0.00 ; \mathrm{N}$, 7.67. Found: C, 23.23; H, 0.00; N, 7.51. EI-MS (positive ion): $\mathrm{m} / z$ 366.8 (calcd for $[\mathrm{M}]^{+}: \mathrm{m} / z$ 366.8), 173.8 (calcd for $\left[\mathrm{NSe}_{2}\right]^{+}: \mathrm{m} / z$ 173.8), 93.9 (calcd for $[\mathrm{NSe}]^{+}: m / z$ 93.9), 79.9 (calcd for $[\mathrm{Se}]^{+}: \mathrm{m} / z$ 79.9), 51.0. IR $\left(\nu_{\max } / \mathrm{cm}^{-1}\right.$; Nujol $): 1648(\mathrm{~m}), 1496(\mathrm{~s}), 1420(\mathrm{~m})$, 1332(s), 1261(m), 1247(m), 1101(m), 994(s), 958(s), 773(s), 763(m), 703(m), 662(m), 636(m).

Synthesis of 2b. 4-Chlorotetrafluorobenzonitrile $(950 \mathrm{mg}, 4.53$ mmol) was added to a solution of $\mathrm{LiN}\left(\mathrm{SiMe}_{3}\right)_{2}(760 \mathrm{mg}, 4.53 \mathrm{mmol})$ in $\mathrm{Et}_{2} \mathrm{O}(50 \mathrm{~mL})$ and the solution stirred for $16 \mathrm{~h}$ at room temperature. The resultant solution was added via cannula to freshly prepared $\mathrm{SeCl}_{2}(4.53 \mathrm{mmol})$ at $0{ }^{\circ} \mathrm{C}$. The reaction was allowed to warm to room temperature and stirred for $5 \mathrm{~h}$ to yield a brown precipitate, which was filtered, washed with ether $(3 \times 20 \mathrm{~mL})$, and dried in vacuo. The crude chloride salt was stirred with silver powder (488 mg, $4.53 \mathrm{mmol})$ in THF $(20 \mathrm{~mL})$ for $18 \mathrm{~h}$, the solvent removed in vacuo, and the crude purple product sublimed $\left(100^{\circ} \mathrm{C}, 10^{-2}\right.$ Torr $)$ onto a water-cooled coldfinger to yield $2 \mathbf{b}$ ( $924 \mathrm{mg}, 54 \%, 2.43 \mathrm{mmol}$ ). Elem anal. Calcd for $\mathrm{C}_{7} \mathrm{ClF}_{4} \mathrm{~N}_{2} \mathrm{Se}_{2}$ : C, 22.04; $\mathrm{H}, 0.00 ; \mathrm{N}, 7.34$. Found: C, 22.39; H, 0.00; N, 7.33. EI-MS (positive ion): $m / z 382.8$ (calcd for $[\mathrm{M}]^{+}: m / z$ 382.8), 209.0 (calcd for $\left[\mathrm{ClC}_{6} \mathrm{~F}_{4} \mathrm{CN}\right]^{+}: \mathrm{m} / z$ 209.0), 173.8 (calcd for $\left[\mathrm{NSe}_{2}\right]^{+}: m / z$ 173.8), 157.8 (calcd for $\left[\mathrm{Se}_{2}\right]^{+}: \mathrm{m} / z$ 157.8, 159.8), 143.0, 109.0, 93.9 (calcd for $[\mathrm{NSe}]^{+}: m / z$ 93.9), 79.9 (calcd for $[\mathrm{Se}]^{+}: m / z$ 79.9), 64.0, 44.0. IR $\left(\nu_{\max } / \mathrm{cm}^{-1} ; \mathrm{Nujol}\right): 1717(\mathrm{~m})$, 1683(m), 1635(m), 1576(m), 1415(m), 1335(m), 1226(w), 976(m), 883(w), 760(m).

Synthesis of $p-\mathrm{BrC}_{6} \mathrm{~F}_{4} \mathrm{CN}_{2} \mathrm{Se}_{2}$ (2c). 4-Bromotetrafluorobenzonitrile $(1.00 \mathrm{~g}, 3.94 \mathrm{mmol})$ was added to a solution of $\mathrm{LiN}\left(\mathrm{SiMe}_{3}\right)_{2}(836$ $\mathrm{mg}, 5.00 \mathrm{mmol})$ in $\mathrm{Et}_{2} \mathrm{O}(50 \mathrm{~mL})$. The mixture was stirred at room temperature for $16 \mathrm{~h}$ and the solution transferred via cannula to freshly prepared $\mathrm{SeCl}_{2}(5.0 \mathrm{mmol})$ at $0{ }^{\circ} \mathrm{C}$. The reaction mixture was allowed to warm to room temperature and stirred for $5 \mathrm{~h}$ to yield a brown precipitate, which was filtered, washed with ether $(3 \times 20 \mathrm{~mL})$, and then dried in vacuo. Half of this crude chloride salt was heated to reflux for $1 \mathrm{~h}$ in $\mathrm{MeCN}(30 \mathrm{~mL})$ with $\mathrm{Ph}_{3} \mathrm{Sb}(380 \mathrm{mg}, 1.08 \mathrm{mmol})$, the solution cooled to room temperature, and the solvent removed in vacuo, and the resulting purple solid was purified by vacuum sublimation $\left(110{ }^{\circ} \mathrm{C}, 10^{-2}\right.$ Torr $)$ onto a water-cooled coldfinger. The process was repeated for the other half of the chloride salt to give 2c (combined yield: $375 \mathrm{mg}, 22 \%, 0.88 \mathrm{mmol}$ ). Elem anal. Calcd for $\mathrm{C}_{7} \mathrm{BrF}_{4} \mathrm{~N}_{2} \mathrm{Se}_{2}$ : C, 19.74; $\mathrm{H}, 0.00 ; \mathrm{N}, 6.58$. Found: C, 20.20; $\mathrm{H}, 0.00 ; \mathrm{N}$, 6.50. EI-MS (positive ion): $m / z 426.1$ (calcd for $[\mathrm{M}]^{+}: \mathrm{m} / z 426.8$ ), 371.0, 307.1, 271.0, 154.1. IR ( $\nu_{\max } / \mathrm{cm}^{-1}$; Nujol): 1633(m), 1406(m), 1334(m), 1261(m), 1218(w), 1095(w), 1018(m), 972(m), 818(w), 752(m), 796(w).

Synthesis of 2d. 4-(Trifluoromethyl)tetrafluorobenzonitrile (243 $\mathrm{mg}, 1 \mathrm{mmol})$ was added to a solution of $\mathrm{LiN}\left(\mathrm{SiMe}_{3}\right)_{2}(167 \mathrm{mg}, 1$ $\mathrm{mmol})$ in $\mathrm{Et}_{2} \mathrm{O}(20 \mathrm{~mL})$ to yield a dark-red reaction mixture, which was stirred for $18 \mathrm{~h}$ at room temperature. The solution was cooled to 0 ${ }^{\circ} \mathrm{C}$ and added to a freshly prepared sample of $\mathrm{SeCl}_{2}(1 \mathrm{mmol})$. The solution was warmed to room temperature and stirred for $5 \mathrm{~h}$, and the red precipitate was filtered, washed with $\mathrm{Et}_{2} \mathrm{O}(2 \times 20 \mathrm{~mL})$, and dried in vacuo. The solid was transferred to a two-limbed reaction vessel separated by a grade 3 sinter, and a $\mathrm{Zn} / \mathrm{Cu}$ couple $(33 \mathrm{mg}, 0.5 \mathrm{mmol}$ ) was added. Liquid $\mathrm{SO}_{2}$ was condensed onto the mixture and the reaction stirred for $18 \mathrm{~h}$ at room temperature. The radical was extracted by repeated washings with $\mathrm{SO}_{2}$ and then $\mathrm{SO}_{2}$ removed to yield a purple solid, which was sublimed $\left(10^{-1}\right.$ Torr, $\left.120^{\circ} \mathrm{C}\right)$ to yield dark crystals of $2 \mathrm{~d}$ suitable for X-ray diffraction $(20 \mathrm{mg}, 5 \%, 0.05$ mmol). EI-MS (positive ion): $m / z 417$ (calcd for $[\mathrm{M}]^{+}: m / z 416.8$ ). Elem anal. Calcd for $\mathrm{C}_{8} \mathrm{~N}_{2} \mathrm{~F}_{7} \mathrm{Se}_{2}: \mathrm{C}, 23.15 ; \mathrm{H}, 0.00 ; \mathrm{N}, 6.75$. Found: $\mathrm{C}$, $22.90 ; \mathrm{H}, 0.00 ; \mathrm{N}, 6.68$.

Synthesis of 2e. 4-Nitrotetrafluorobenzonitrile (500 mg, 2.27 $\mathrm{mmol})$ was added to a solution of $\mathrm{LiN}\left(\mathrm{SiMe}_{3}\right)_{2}(380 \mathrm{mg}, 2.27 \mathrm{mmol})$ in $\mathrm{Et}_{2} \mathrm{O}(40 \mathrm{~mL})$ to form a dark-red solution, which was stirred for 18 $\mathrm{h}$ at room temperature. The solution was cooled to $0{ }^{\circ} \mathrm{C}$ and added to a freshly prepared sample of $\mathrm{SeCl}_{2}(2.27 \mathrm{mmol})$. The solution was allowed to warm to room temperature and stirred for $5 \mathrm{~h}$. The resultant red precipitate was filtered, washed with $\mathrm{Et}_{2} \mathrm{O}(2 \times 20 \mathrm{~mL})$, and dried in vacuo. Silver powder $(245 \mathrm{mg}, 2.27 \mathrm{mmol})$ and THF (20 $\mathrm{mL}$ ) were added to the solid. The solution was stirred at room temperature for $18 \mathrm{~h}$ to yield a purple solution. The solvent was removed in vacuo to yield a dark solid, which was sublimed $\left(10^{-2}\right.$ Torr, $120^{\circ} \mathrm{C}$ ) to yield dark crystals of $2 \mathrm{e}$ suitable for X-ray diffraction (45 mg, 5\%, $0.11 \mathrm{mmol}$ ). Elem anal. Calcd for $\mathrm{C}_{7} \mathrm{~N}_{3} \mathrm{O}_{2} \mathrm{~F}_{4} \mathrm{Se}_{2}$ : C, 21.37; H, 0; N, 10.68. Found: C, 21.40; H, 0.14; N, 10.42. EI-MS (positive ion): $m / z 394$ (calcd for $[\mathrm{M}]^{+}: m / z$ 393.8), 348, 237, 207, 174 (calcd for $\left[\mathrm{NSe}_{2}\right]^{+}: m / z$ 173.8; calcd for $\left[\mathrm{C}_{6} \mathrm{~F}_{4} \mathrm{CN}\right]^{+}: m / z$ 174.0).

Synthesis of $2 \mathrm{f}$. A solution of $\mathrm{LiN}\left(\mathrm{SiMe}_{3}\right)_{2}(836 \mathrm{mg}, 5.00 \mathrm{mmol})$ in $\mathrm{Et}_{2} \mathrm{O}(60 \mathrm{~mL})$ was transferred via cannula to a suspension of tetrafluoroterephthalonitrile $(1 \mathrm{~g}, 5.00 \mathrm{mmol})$ in $\mathrm{Et}_{2} \mathrm{O}(15 \mathrm{~mL})$ and the solution stirred at room temperature for $16 \mathrm{~h}$. The solution was then transferred via cannula at $0{ }^{\circ} \mathrm{C}$ to freshly prepared $\mathrm{SeCl}_{2}$ (5.0 $\mathrm{mmol})$. The reaction mixture was allowed to warm to room temperature and stirred for $64 \mathrm{~h}$. The brown precipitate was filtered, washed with $\mathrm{Et}_{2} \mathrm{O}(3 \times 10 \mathrm{~mL})$, and dried in vacuo. $\mathrm{Ph}_{3} \mathrm{Sb}(558 \mathrm{mg}$, $1.60 \mathrm{mmol}$ ) was added to the crude chloride salt, followed by $\mathrm{MeCN}$ $(20 \mathrm{~mL})$. The reaction mixture was heated to reflux for $1 \mathrm{~h}$ and cooled to room temperature. The solvent was removed under vacuum and the resulting purple solid sublimed $\left(125^{\circ} \mathrm{C}, 10^{-2}\right.$ Torr $)$ for $3 \mathrm{~h}$ onto a water-cooled coldfinger to yield $2 \mathrm{f}(240 \mathrm{mg}, 13 \%, 0.64 \mathrm{mmol})$. Elem anal. Calcd for $\mathrm{C}_{8} \mathrm{~F}_{4} \mathrm{~N}_{3} \mathrm{Se}_{2}$ : C, 25.83; $\mathrm{H}, 0.00 ; \mathrm{N}, 11.30$. Found: $\mathrm{C}$, 26.38; H, 0.19; N, 10.90. EI-MS (positive ion): $m / z 373.8$ (calcd for $\left.[\mathrm{M}]^{+}: m / z 373.8\right), 173.8\left(\right.$ calcd for $\left.\left[\mathrm{NSe}_{2}\right]^{+}: m / z 173.8\right), 159.8$ (calcd for $\left[\mathrm{Se}_{2}\right]^{+}: m / z 159.8$ ), 93.9 (calcd for $[\mathrm{NSe}]^{+}: m / z$ 93.9), 79.9 (calcd for $[\mathrm{Se}]^{+}: \mathrm{m} / z$ 79.9). IR $\left(\nu / \mathrm{cm}^{-1}\right.$; Nujol): 2250(w,CN), 1644(w), 1488(s), 1435(s), 1331(s), 1262(m), 1058(m), 996(s), 926(w), 800(w), 772(m), 762(m), 734(m), 712(w), 685(w), 670(w), 642(w).

Synthesis of 2,4,6-( $\left(\mathrm{CF}_{3}\right)_{3} \mathrm{C}_{6} \mathrm{H}_{2} \mathrm{CN}_{2} \mathrm{Se}_{2}$ (2g). 1,3,5-Tris(trifluoromethyl)benzene $(2.82 \mathrm{~g}, 10 \mathrm{mmol})$ was added to a solution of ${ }^{n} \mathrm{BuLi}(6.25 \mathrm{~mL}$ of $1.6 \mathrm{M}$ solution in hexanes, $10 \mathrm{mmol})$ in $\mathrm{Et}_{2} \mathrm{O}(20$ $\mathrm{mL}$ ) at $0{ }^{\circ} \mathrm{C}$ to yield a cloudy yellow solution. This was stirred for $2 \mathrm{~h}$ at room temperature, after which time bis(trimethylsilyl)carbodiimide $(1.86 \mathrm{~g}, 10 \mathrm{mmol})$ was added to yield an orange solution, which was stirred for $2 \mathrm{~h}$. The solvent was removed in vacuo to yield an orange oil. This oil was redissolved in toluene $(20 \mathrm{~mL})$, cooled to $0{ }^{\circ} \mathrm{C}$, and added to a freshly prepared sample of $\mathrm{SeCl}_{2}(10 \mathrm{mmol})$. The solution was warmed to room temperature and stirred for $18 \mathrm{~h}$, and the resultant red precipitate was filtered, washed with $\mathrm{Et}_{2} \mathrm{O}(2 \times 20 \mathrm{~mL})$, and dried in vacuo. The solid was transferred to a two-limbed reaction vessel separated by a grade 3 sinter and a $\mathrm{Zn} / \mathrm{Cu}$ couple $(325 \mathrm{mg}, 5$ $\mathrm{mmol}$ ) added. Liquid $\mathrm{SO}_{2}$ was condensed onto the mixture and the reaction stirred for $18 \mathrm{~h}$ at room temperature. The radical was extracted by repeated washings with $\mathrm{SO}_{2}$ and then $\mathrm{SO}_{2}$ removed to yield a purple solid, which was then sublimed $\left(10^{-1} \mathrm{Torr}, 100^{\circ} \mathrm{C}\right)$ to yield blue crystals of $2 \mathrm{~g}$ suitable for X-ray diffraction $(20 \mathrm{mg}, 0.5 \%$, $0.04 \mathrm{mmol}$ ). EI-MS (positive ion): $\mathrm{m} / z 481$ (calcd for $[\mathrm{M}]^{+}: \mathrm{m} / z$ 480.8), 307 (calcd for $\left[\left(\mathrm{CF}_{3}\right)_{3} \mathrm{C}_{6} \mathrm{H}_{2} \mathrm{CN}\right]^{+}: \mathrm{m} / z$ 307.0), 288 (calcd for $\left.\left[\mathrm{C}_{3} \mathrm{~F}_{8} \mathrm{C}_{6} \mathrm{H}_{2} \mathrm{CN}\right]^{+}: m / z 288.0\right), 238$ (calcd for $\left[\left(\mathrm{CF}_{3}\right)_{2} \mathrm{C}_{6} \mathrm{H}_{2} \mathrm{CN}\right]^{+}: \mathrm{m} / z$ 238.0).

X-ray Crystallography. Crystals of $2 a-2 g$ suitable for X-ray diffraction were all grown by slow sublimation under static vacuum $\left(10^{-2}\right.$ Torr $)$ in glass sublimation tubes. Crystals were coated in paratone oil and mounted on the end of a glass fiber with fluoropolymer. Data for $\mathbf{2 a}, \mathbf{2 d}$, and $\mathbf{2 f}$ were collected on a Rigaku AFC7R diffractometer equipped with a Mo $\operatorname{Ko}(\lambda=0.7107 \AA)$ rotating-anode source using $\psi$ scans. Data were corrected for absorption using $\psi$ scans. ${ }^{42}$ Data for $2 \mathbf{b}, 2 \mathbf{e}$, and $2 \mathrm{~g}$ were collected on a Nonius Kappa CCD diffractometer with a CCD detector using graphite-monochromated Mo K $\alpha$ radiation. Data were collected using COLLECT ${ }^{43}$ and integrated and reduced using HKL, DENZO, and SCALEPACK ${ }^{44}$ A multiscan absorption correction was applied using SORTAV. ${ }^{45}$ In all cases, the sample temperature was maintained using an Oxford Cryosystems Cryostream. All structures were solved by direct methods and refined against $F^{2}$ using the SHELXTL package. ${ }^{46}$ Unit cell parameters and refinement statistics are presented in the SI. The structure of $2 \mathrm{c}$ has been reported previously. ${ }^{47}$ All new structures 
have been deposited with the Cambridge Crystallographic Data Centre (CCDC 1421399-1421404).

Computational Studies. All calculations were undertaken using Jaguar $v 8.7^{48}$ with surfaces visualized within Maestro $10.1 .^{49}$ All

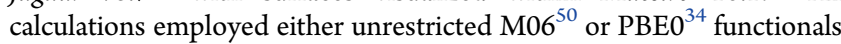
and included a dispersion correction using the D3 method of Grimme. ${ }^{51}$ The cc-PVTZ-PP(-F)++ basis set, ${ }^{52}$ which comprises a correlation-consistent triple- $\zeta$ basis set incorporating both polarization and diffuse functions, was implemented for all calculations. For calculations of the cis-cofacial, trans-antarafacial, and orthogonal modes of association for $[\mathrm{HCNSeSeN}]_{2}$, full geometry optimization was undertaken, commencing from a structure adapted from the crystallographic data in which the aryl group was replaced by hydrogen within Mercury. ${ }^{53}$ Dipole moments were computed on the gas-phaseoptimized geometries of radicals $2 \mathrm{a}-2 \mathrm{~g}$. The strength of the intermolecular chain-forming $\mathrm{CN} \cdots \mathrm{Se}$ interactions in $\mathbf{2 f}$ employed single-point calculations on the dimer pair and the isolated radical using the crystallographically determined geometry. TD-DFT calculations were undertaken on the geometry-optimized structure of 2a, with the 55 lowest-energy transitions covering the spectrum from 650 to $200 \mathrm{~nm}$. Spectra were visualized and compared to experimental data $\left(1 \times 10^{-4} \mathrm{M}\right)$ within Maestro. Transition energies were scaled by a factor of 0.95 to give a best fit to the experimental data, and the experimental line width was optimized to fit the intense transitions at 369 and $433 \mathrm{~nm}$.

\section{ASSOCIATED CONTENT}

\section{S Supporting Information}

The Supporting Information is available free of charge on the ACS Publications website at DOI: 10.1021/acs.inorgchem.6b01771.

EPR analysis of the spin-density distribution, summary of crystallographic data, magnetic data for compounds $\mathbf{2 b}$ and $\mathbf{2 c}$, and a linear fit of the absorbance versus concentration for the peak at $369 \mathrm{~nm}$ (PDF) $\mathrm{X}$-ray crystallographic data in CIF format for 2a (CIF) $\mathrm{X}$-ray crystallographic data in CIF format for $\mathbf{2 b}$ (CIF) $\mathrm{X}$-ray crystallographic data in CIF format for $\mathbf{2 d}$ (CIF) $\mathrm{X}$-ray crystallographic data in CIF format for $2 \mathbf{e}$ (CIF) $\mathrm{X}$-ray crystallographic data in CIF format for $\mathbf{2 g}$ (CIF)

\section{AUTHOR INFORMATION}

\section{Corresponding Authors}

*E-mail: MelenR@cardiff.ac.uk.

*E-mail: jmrawson@uwindsor.ca.

\section{Author Contributions}

The manuscript was written through contributions from all authors. All authors have given approval to the final version of the manuscript.

\section{Notes}

The authors declare no competing financial interest.

\section{ACKNOWLEDGMENTS}

R.J.L. and C.M.P. thank the University of Cambridge and EPSRC for financial support. R.L.M. thanks the University of Cambridge for a Domestic Research Scholarship. J.M.R. thanks the EPSRC and NSERC Discovery Grant and RTI programs as well as the Canada Research Chairs program for funding. We particularly thank Dr. J. E. Davies for crystallographic data collection and Dr. A. D. Bond (University of Cambridge) for assistance with the crystallographic data. We thank P. Oliete and F. Palacio (Universidad de Zaragoza) for magnetic measurements on $\mathbf{2 b}$ and $2 c^{47}$

\section{REFERENCES}

(1) Banister, A. J.; Bricklebank, N.; Lavender, I.; Rawson, J. M.; Gregory, C. I.; Tanner, B. K.; Clegg, W.; Elsegood, M. R. J.; Palacio, F. Spontaneous Magnetization in a Sulfur-Nitrogen Radical at $36 \mathrm{~K}$. Angew. Chem., Int. Ed. Engl. 1996, 35, 2533-2535. (b) Thomson, R. I.; Pask, C. M.; Lloyd, G. O.; Mito, M.; Rawson, J. M. Pressure-Induced Enhancement of Magnetic-Ordering Temperature in an Organic Radical to $70 \mathrm{~K}$ : A Magnetostructural Correlation. Chem. - Eur. J. 2012, 18, 8629-8633. (c) Palacio, F.; Antorrena, G.; Castro, M.; Burriel, R.; Rawson, J. M.; Smith, J. N. B.; Bricklebank, N.; Novoa, J.; Ritter, C. High-Temperature Magnetic Ordering in a New Organic Magnet. Phys. Rev. Lett. 1997, 79, 2336-2339.

(2) Alberola, A.; Less, R. J.; Pask, C. M.; Rawson, J. M.; Palacio, F.; Oliete, P.; Paulsen, C.; Yamaguchi, A.; Farley, R. D.; Murphy, D. M. A thiazyl-based organic ferromagnet. Angew. Chem., Int. Ed. 2003, 42, $4782-4785$.

(3) Cordes, A. W.; Haddon, R. C.; Oakley, R. T. Molecular conductors from neutral heterocyclic $\pi$-radicals. Adv. Mater. 1994, 6, 798-802.

(4) Vegas, A.; Pérez-Salazar, A.; Banister, A. J.; Hey, R. G. Crystal structure of 4-phenyl-1,2-dithia-3,5-diazole dimer. J. Chem. Soc., Dalton Trans. 1980, 1812-1815.

(5) Preuss, K. E. Metal-radical coordination complexes of thiazyl and selenazyl ligands. Coord. Chem. Rev. 2015, 289-290, 49-61.

(6) Haynes, D. A. Crystal engineering with dithiadiazolyl radicals. CrystEngComm 2011, 13, 4793-4805.

(7) Gillespie, R. J.; Kent, J. P.; Sawyer, J. F. Monomeric and dimeric thiodithiazyl cations, $\mathrm{S}_{3} \mathrm{~N}_{2}^{+}$and $\mathrm{S}_{6} \mathrm{~N}_{4}{ }^{2+}$. Preparation and crystal structures of $\left(\mathrm{S}_{3} \mathrm{~N}_{2}\right)\left(\mathrm{AsF}_{6}\right),\left(\mathrm{S}_{6} \mathrm{~N}_{4}\right)\left(\mathrm{S}_{2} \mathrm{O}_{2} \mathrm{~F}\right)_{2}$ and $\left(\mathrm{S}_{6} \mathrm{~N}_{4}\right)\left(\mathrm{SO}_{3} \mathrm{~F}\right)_{2}$. Inorg. Chem. 1981, 20, 3784-3799.

(8) (a) Gleiter, R.; Bartetzko, R; Hofmann, P. The Structure of Thiodithiazyl Derivatives An Example of an Electron-Rich-FourCenter-Bond. Z. Naturforsch., B: J. Chem. Sci. 1980, 35, 1166-1170. (b) Gleiter, R; Haberhauer, G. Long Chalcogen-Chalcogen Bonds in Electron-Rich Two and Four Center Bonds: Combination of $\pi$ - and $\sigma$ Aromaticity to a Three-Dimensional $\sigma / \pi$-Aromaticity. J. Org. Chem. 2014, 79, 7543-7552.

(9) Domagala, S.; Kosc, K.; Robinson, S. W.; Haynes, D. A.; Wozniak, K. Dithiadiazolyl Radicals-Structures and Charge Densities of Their Crystals and Co-Crystal. Cryst. Growth Des. 2014, 14, 48344848.

(10) (a) Decken, A.; Cameron, T. S.; Passmore, J.; Rautiainen, J. M.; Reed, R. W.; Shuvaev, K. V.; Thompson, L. K. Toward a More General Synthetic Route to Paramagnetic Solids Containing RCNSSS ${ }^{\bullet+}$ Radical Cations. A Structure-Property Correlation for $\mathrm{RCNSSS}^{\bullet+}$ $\left(\mathrm{R}=\mathrm{F}_{5} \mathrm{C}_{2}, \mathrm{Cl}_{3} \mathrm{C}\right)$. Inorg. Chem. 2007, 46, 7436-7457. (b) Shuvaev, $\mathrm{K}$. V.; Decken, A.; Grein, F.; Abedin, T. S. M.; Thompson, L. K.; Passmore, J. NC. $\left(\mathrm{CF}_{2}\right)_{4} \cdot \mathrm{CNSSN}$ containing 1,2,3,5-dithiadiazolyl radical dimer exhibiting triplet excited states at low temperature and thermal hysteresis on melting-solidification: structural, spectroscopic, and magnetic characterization. Dalton Trans. 2008, 4029-4037.

(11) (a) Constantinides, C. P.; Eisler, D. J.; Alberola, A.; Carter, E.; Murphy, D. M.; Rawson, J. M. Weakening of the $\pi^{*}-\pi^{*}$ dimerisation in 1,2,3,5-dithiadiazolyl radicals: structural, EPR, magnetic and computational studies of dichlorophenyl dithiadiazolyls, $\mathrm{Cl}_{2} \mathrm{C}_{6} \mathrm{H}_{3}$ CNSSN. CrystEngComm 2014, 16, 7298-7312. (b) Beldjoudi, Y.; Haynes, D. A.; Hayward, J. J.; Manning, W. J.; Pratt, D. R.; Rawson, J. M. Preparation and crystal structures of the isomeric series 4-tolyl1,2,3,5-dithiadiazolyl, $\left(o-\mathrm{MeC}_{6} \mathrm{H}_{4} \mathrm{CNSSN}\right)_{2},\left(m-\mathrm{MeC}_{6} \mathrm{H}_{4} \mathrm{CNSSN}\right)_{2}$ and $\left(p-\mathrm{MeC}_{6} \mathrm{H}_{4} \mathrm{CNSSN}\right)_{2}$. CrystEngComm 2013, 15, 1107-1113.

(12) Beneberu, H. Z.; Tian, Y.-H.; Kertesz, M. Bonds or not bonds? Pancake bonding in 1,2,3,5-dithiadiazolyl and 1,2,3,5-diselenadiazolyl radical dimers and their derivatives. Phys. Chem. Chem. Phys. 2012, 14, 10713-10725.

(13) Preuss, K. E. Pancake bonds: $\pi$-Stacked dimers of organic and light-atom radicals. Polyhedron 2014, 79, 1-15.

(14) (a) Cordes, A. W.; Haddon, R. C.; Oakley, R. T.; Schneemeyer, L. F.; Waszczak, J. A.; Young, K. M.; Zimmerman, N. M. Molecular semiconductors from bifunctional dithia- and diselenadiazolyl radicals. 
Preparation and solid-state structural and electronic properties of 1,4$\left[\left(\mathrm{E}_{2} \mathrm{~N}_{2} \mathrm{C}\right) \mathrm{C}_{6} \mathrm{H}_{4}\left(\mathrm{CN}_{2} \mathrm{E}_{2}\right)\right]$ (E = sulfur, selenium). J. Am. Chem. Soc. 1991, 113, 582-588. (b) Andrews, M. P.; Cordes, A. W.; Douglass, D. C.; Fleming, R. M.; Glarum, S. H.; Haddon, R. C.; Marsh, P.; Oakley, R. T.; Palstra, T. T. M.; Schneemeyer, L. F.; Trucks, G. W.; Tycko, R. R.; Waszczak, J. V.; Warren, W. W.; Young, K. M.; Zimmerman, N. M. One-dimensional stacking of bifunctional dithia- and diselenadiazolyl radicals: preparation and structural and electronic properties of 1,3$\left[\left(\mathrm{E}_{2} \mathrm{~N}_{2} \mathrm{C}\right) \mathrm{C}_{6} \mathrm{H}_{4}\left(\mathrm{CN}_{2} \mathrm{E}_{2}\right)\right]$ (E = sulfur, selenium). J. Am. Chem. Soc. 1991, 113, 3559-3568. (c) Cordes, A. W.; Haddon, R. C.; Hicks, R. G.; Oakley, R. T.; Palstra, T. T. M. Preparation and solid-state structures of (cyanophenyl)dithia- and (cyanophenyl)diselenadiazolyl radicals. Inorg. Chem. 1992, 31, 1802-1808. (d) Cordes, A. W.; Haddon, R. C.; Hicks, R. G.; Kennepohl, D. K.; Oakley, R. T.; Palstra, T. T. M.; Schneemeyer, L. F.; Scott, S. R.; Waszczak, J. V. Preparation and solid-state structural, electronic, and magnetic properties of the 5cyano-1,3-benzene-bridged bis(1,2,3,5-dithiadiazolyl) and bis(1,2,3,5diselenadiazolyl) [5-CN-1,3- $\left.\mathrm{C}_{6} \mathrm{H}_{3}\left(\mathrm{CN}_{2} \mathrm{E}_{2}\right)_{2}\right](\mathrm{E}=\mathrm{S}, \mathrm{Se})$. Chem. Mater. 1993, 5, 820-825.

(15) (a) Winter, S. M.; Hill, S.; Oakley, R. T. Magnetic Ordering and Anisotropy in Heavy Atom Radicals. J. Am. Chem. Soc. 2015, 137, 3720-3730. (b) Thirunavukkuarasu, K.; Winter, S. M.; Beedle, C. C.; Kovalev, A. E.; Oakley, R. T.; Hill, S. Pressure dependence of the exchange anisotropy in an organic ferromagnet. Phys. Rev. B: Condens. Matter Mater. Phys. 2015, 91, 014412. (c) Lekin, K.; Leitch, A. A.; Tse, J. S.; Bao, X.; Secco, R. A.; Desgreniers, S.; Ohishi, Y.; Oakley, R. T. A Pressure Induced Structural Dichotomy in Isostructural Bis-1,2,3thiaselenazolyl Radical Dimers. Cryst. Growth Des. 2012, 12, 46764684. (d) Winter, S. M.; Oakley, R. T.; Kovalev, A. E.; Hill, S. Spinorbit effects in heavy-atom organic radical ferromagnets. Phys. Rev. B: Condens. Matter Mater. Phys. 2012, 85, 094430. (e) Winter, S. M.; Datta, S.; Hill, S.; Oakley, R. T. Magnetic Anisotropy in a Heavy Atom Radical Ferromagnet. J. Am. Chem. Soc. 2011, 133, 8126-8129. (f) Leitch, A. A.; Lekin, K.; Winter, S. M.; Downie, L. E.; Tsuruda, H.; Tse, J. S.; Mito, M.; Desgreniers, S.; Dube, P. A.; Zhang, S.; Liu, Q.; Jin, C.; Ohishi, Y.; Oakley, R. T. From Magnets to Metals: The Response of Tetragonal Bisdiselenazolyl Radicals to Pressure. J. Am. Chem. Soc. 2011, 133, 6051-6060. (g) Tsuruda, H.; Mito, M.; Deguchi, H.; Takagi, S.; Leitch, A. A.; Lekin, K.; Winter, S. M.; Oakley, R. T. Pressure dependence of Curie temperature in a selenazyl radical ferromagnet. Polyhedron 2011, 30, 2997-3000. (h) Mito, M.; Komorida, Y.; Tsuruda, H.; Tse, J. S.; Desgreniers, S.; Ohishi, Y.; Leitch, A. A.; Cvrkalj, K.; Robertson, C. M.; Oakley, R. T. Heavy Atom Ferromagnets under Pressure: Structural Changes and the Magnetic Response. J. Am. Chem. Soc. 2009, 131, 16012-16013. (i) Leitch, A. A.; Yu, X.; Robertson, C. M.; Secco, R. A.; Tse, J. S.; Oakley, R. T. Isostructural Bis-1,2,3-Thiaselenazolyl Dimers. Inorg. Chem. 2009, 48, 9874-9882. (j) Leitch, A. A.; Yu, X.; Winter, S. M.; Secco, R. A.; Dube, P. A.; Oakley, R. T. Structure and Property Correlations in Heavy Atom Radical Conductors. J. Am. Chem. Soc. 2009, 131, 71127125. (k) Robertson, C. M.; Leitch, A. A.; Cvrkalj, K.; Myles, D. J. T.; Reed, R. W.; Dube, P. A.; Oakley, R. T. Ferromagnetic Ordering in Bisthiaselenazolyl Radicals: Variations on a Tetragonal Theme. J. Am. Chem. Soc. 2008, 130, 14791-14801. (1) Robertson, C. M.; Leitch, A. A.; Cvrkalj, K.; Reed, R. W.; Myles, D. J. T.; Dube, P. A.; Oakley, R. T. Enhanced Conductivity and Magnetic Ordering in Isostructural Heavy Atom Radicals. J. Am. Chem. Soc. 2008, 130, 8414-8425.

(16) Blundell, S. Magnetism in condensed matter; Oxford University Press: Oxford, U.K., 2001.

(17) (a) Antorrena, G.; Davies, J. E.; Hartley, M.; Palacio, F.; Rawson, J. M.; Smith, J. N. B.; Steiner, A. A novel paramagnetic dithiadiazolyl radical: Crystal structure and magnetic properties of $p$ $\mathrm{BrC}_{6} \mathrm{~F}_{4} \mathrm{CNSSN}^{\bullet}$. Chem. Commun. 1999, 1393-1394. (b) Alberola, A.; Less, R. J.; Palacio, F.; Pask, C. M.; Rawson, J. M. Synthesis and magnetic properties of the novel dithiadiazolyl radical, $p$ $\mathrm{NCC}_{6} \mathrm{~F}_{4} \mathrm{C}_{6} \mathrm{~F}_{4} \mathrm{CNSSN}$. Molecules 2004, 9, 771-781. (c) Alberola, A.; Clarke, C. S.; Haynes, D. A.; Pascu, S. I.; Rawson, J. M. Crystal structures and magnetic properties of a sterically encumbered dithiadiazolyl radical, 2,4,6-( $\left.\mathrm{F}_{3} \mathrm{C}\right)_{3} \mathrm{C}_{6} \mathrm{H}_{2} \mathrm{CNSSN}^{\bullet}$. Chem. Commun. 2005, 4726-4727.

(18) Del Bel Belluz, P.; Cordes, A. W.; Kristof, E. M.; Kristof, P. V.; Liblong, S. W.; Oakley, R. T. 1,2,3,5-Diselenadiazolyls as Building Blocks for Molecular Metals. Preparation and Structures of $\left[\mathrm{PhCN}_{2} \mathrm{Se}_{2}\right]^{+} \mathrm{PF}_{6}{ }^{-}$and $\left[\mathrm{PhCN}_{2} \mathrm{Se}_{2}\right]_{2}$. J. Am. Chem. Soc. 1989, 111, 9276-9278.

(19) (a) Boere, R. T. Short contacts of the sulphur atoms of a $1,2,3,5$ dithiadiazolyl dimer with triphenylstibine: first cocrystal with an aromatic compound. CrystEngComm 2016, 18, 2748-2756. (b) Mills, M. B.; Hollingshead, A. G.; Maahs, A. C.; Soldatov, D.; Preuss, K. E. Isomerization of a lanthanide complex using a humming top guest template: a solid-to-solid reaction. CrystEngComm 2015, 17, 78167819.

(20) Awere, E.; Passmore, J.; Preston, K. F.; Sutcliffe, L. H. A comparative electron spin resonance study of the selenothiadiazolyl radicals cyclo- $\mathrm{Se}_{3-n} \mathrm{~S}_{n} \mathrm{~N}_{2}^{+}(n=0-3)$. Can. J. Chem. 1988, 66, 17761780.

(21) Fairhurst, S. A.; Sutcliffe, L. H.; Preston, K. F.; Banister, A. J.; Partington, A. S.; Rawson, J. M.; Passmore, J.; Schriver, M. J. Electron spin resonance spectroscopy of $\mathrm{CF}_{3} \mathrm{CNSSN}^{\bullet}$ and $\mathrm{C}_{6} \mathrm{~F}_{5} \mathrm{CNSSN}^{\bullet}$ free radicals. Magn. Reson. Chem. 1993, 31, 1027-1030.

(22) Luzon, J.; Campo, J.; Palacio, F.; McIntyre, G. J.; Rawson, J. M.; Less, R. J.; Pask, C. M.; Alberola, A.; Farley, R. D.; Murphy, D. M.; Goeta, A. E. Spin density studies on $p-\mathrm{O}_{2} \mathrm{NC}_{6} \mathrm{~F}_{4} \mathrm{CNSSN}$ : A heavy $p$ block organic ferromagnet. Phys. Rev. B: Condens. Matter Mater. Phys. 2010, 81, 144429.

(23) (a) Fairhurst, S. A.; Johnson, K. M.; Sutcliffe, L. H.; Preston, K. F.; Banister, A. J.; Hauptman, Z. V.; Passmore, J. Electron spin resonance study of $\mathrm{CH}_{3} \mathrm{CNSSN}^{\bullet}, \mathrm{C}_{6} \mathrm{H}_{5} \mathrm{CNSSN}^{\bullet}$, and $\mathrm{SNSSN}^{\bullet+}$ free radicals. J. Chem. Soc., Dalton Trans. 1986, 1465-1472. (b) Brooks, W. V. F.; Burford, N.; Passmore, J.; Schriver, M. J.; Sutcliffe, L. H. Paramagnetic liquids: the preparation and characterisation of the thermally stable radical $\mathrm{Bu}^{t} \mathrm{CNSNS}{ }^{\bullet}$ and its quantitative photochemically symmetry allowed rearrangement to a second stable radical $\mathrm{Bu}^{\mathrm{t} C N S S N}{ }^{\bullet}$. J. Chem. Soc., Chem. Commun. 1987, 0, 69-71.

(24) Britten, J.; Hearns, N. G. R.; Preuss, K. E.; Richardson, J. F.; BinSalamon, $\mathrm{S}$. $\mathrm{Mn}$ (II) and $\mathrm{Cu}$ (II) Complexes of a Dithiadiazolyl Radical Ligand: Monomer/Dimer Equilibria in Solution. Inorg. Chem. 2007, 46, 3934-3945.

(25) Davies, J. E.; Less, R. J.; May, I.; Rawson, J. M. Isolation of the first diselenadiazolyl complex, $\mathrm{Pd}_{3}[\mathrm{PhCNSeSeN}]_{2}\left[\mathrm{PPh}_{3}\right]_{4} \cdot 2 \mathrm{PhMe}$. New J. Chem. 1998, 22, 763-765.

(26) (a) Cordes, A. W.; Haddon, R. C.; Hicks, R. G.; Oakley, R. T.; Palstra, T. T. M.; Schneemeyer, L. F.; Waszczak, J. V. Polymorphism of 1,3-Phenylene Bis(diselenadiazolyl). Solid-state Structural and Electronic Properties of b-1,3-[( $\left.\left.\mathrm{Se}_{2} \mathrm{~N}_{2} \mathrm{C}\right) \mathrm{C}_{6} \mathrm{H}_{4}\left(\mathrm{CN}_{2} \mathrm{Se}_{2}\right)\right]$. J. Am. Chem. Soc. 1992, 114, 1729-1732. (b) Davis, W. M.; Hicks, R. G.; Oakley, R. T.; Zhao, B.; Taylor, N. J. Solid state intermolecular interactions in cyanofunctionalized diselenadiazolyl dimers. Can. J. Chem. 1993, 71, 180-185. (c) Beer, L.; Cordes, A. W.; Myles, D. J. T.; Oakley, R. R.; Taylor, N. J. 1,2,3,5-Dithiadiazolyls and 1,2,3,5-diselenadiazolyls; stacking and packing of $\pi$-dimers. CrystEngComm 2000, 2, 109-114. (d) Parvez, M.; Boere, R. T.; Moock, K. H. A Dimer of 4-(4Methoxyphenyl)-1,2,3,5-diselenadiazole. Acta Crystallogr., Sect. C: Cryst. Struct. Commun. 1995, 51, 2118. (e) Cordes, A. W.; Glarum, S. H.; Haddon, R. C.; Hallford, R.; Hicks, R. G.; Kennepohl, D. K.; Oakley, R. T.; Palstra, T. T. M.; Scott, S. R. Preparation and solid state characterization of $1,2,3,5$-diselenadiazolyl $\left[\mathrm{HCN}_{2} \mathrm{Se}_{2}\right]^{\bullet}$. J. Chem. Soc., Chem. Commun. 1992, 1265-1266. (f) Britten, J. F.; Clements, O. P.; Cordes, A. W.; Haddon, R. C.; Oakley, R. T.; Richardson, J. F. Stacking Efficiency of Diselenadiazolyl $\pi$-Dimers. Consequences for Electronic Structure and Transport Properties. Inorg. Chem. 2001, 40, $6820-6824$

(27) Clarke, C. S.; Haynes, D. A.; Smith, J. N. B.; Batsanov, A.; Howard, J. A. K.; Pascu, S. I.; Rawson, J. M. The effect of fluorinated aryl substituents on the crystal structures of 1,2,3,5-dithiadiazolyl radicals. CrystEngComm 2010, 12, 172-185. 
(28) Bond, A. D.; Haynes, D. A.; Pask, C. M.; Rawson, J. M. Concomitant polymorphs: structural studies on the trimorphic dithiadiazolyl radical, ClCNSSN ${ }^{\bullet}$. J. Chem. Soc., Dalton Trans. 2002, 2522-2531.

(29) Nyburg, S. C.; Faerman, C. H. A revision of van der Waals atomic radii for molecular crystals: $\mathrm{N}, \mathrm{O}, \mathrm{F}, \mathrm{S}, \mathrm{Cl}, \mathrm{Se}, \mathrm{Br}$ and $\mathrm{I}$ bonded to carbon. Acta Crystallogr., Sect. B: Struct. Sci. 1985, 41, 274-279.

(30) Pask, C. M. Magneto-structural correlations of some novel sulfur-nitrogen radicals. Ph.D. Thesis, University of Cambridge, Cambridge, U.K., 2003.

(31) Alberola, A.; Carter, E.; Constantinides, C. P.; Eisler, D. J.; Murphy, D. M.; Rawson, J. M. Crystal structures, EPR and magnetic properties of $2-\mathrm{ClC}_{6} \mathrm{H}_{4} \mathrm{CNSSN}^{\bullet}$ and $2,5-\mathrm{Cl}_{2} \mathrm{C}_{6} \mathrm{H}_{3} \mathrm{CNSSN}{ }^{\bullet}$. Chem. Commun. 2011, 47, 2532-2534.

(32) Cordes, A. W.; Bryan, C. D.; Davis, W. M.; de Laat, R. H.; Glarum, S. H.; Goddard, J. D.; Haddon, R. C.; Hicks, R. G.; Kennepohl, D. K. Prototypal 1,2,3,5-Dithia- and 1,2,3,5-Diselenadiazolyl $\left[\mathrm{HCN}_{2} \mathrm{E}_{2}\right]^{\bullet}(\mathrm{E}=\mathrm{S}, \mathrm{Se})$ : Molecular and Electronic Structures of the Radicals and Their Dimers, by Theory and Experiment. J. Am. Chem. Soc. 1993, 115, 7232-7239.

(33) (a) Zhao, Y.; Truhlar, D. G. Acc. Chem. Res. 2008, 41, 157; Acc. Chem. Res. 2008, 41, 157-167. (b) Zhao, Y.; Truhlar, D. G. Density Functional for Spectroscopy: No Long-Range Self-Interaction Error, Good Performance for Rydberg and Charge-Transfer States, and Better Performance on Average than B3LYP for Ground States. J. Phys. Chem. A 2006, 110, 13126-13130.

(34) Adamo, C.; Barone, V. Toward reliable density functional methods without adjustable parameters: The PBE0 model. J. Chem. Phys. 1999, 110, 6158-6170.

(35) Grimme, S. Wiley Interdisciplinary Reviews: Computational Molecular Science 2011, 1, 211-228.

(36) Allen, F. H.; Harris, S. E.; Taylor, R. Comparison of conformer distributions in the crystalline state with conformational energies calculated by ab initio techniques. J. Comput.-Aided Mol. Des. 1996, 10, 247.

(37) Bryan, C. D.; Cordes, A. W.; Oakley, R. T.; Spence, R. E. v. H. 4,4'-Dimethyl-1,1'-bi(1,2,3,5-diselenadiazole). Acta Crystallogr., Sect. C: Cryst. Struct. Commun. 1995, 51, 2402-2404.

(38) Wu, J.; MacDonald, D. J.; Clerac, R.; Jeon, I.-R.; Jennings, M.; Lough, A. J.; Britten, J.; Robertson, C.; Dube, P. A.; Preuss, K. E. Metal Complexes of Bridging Neutral Radical Ligands: pymDTDA and pymDSDA. Inorg. Chem. 2012, 51, 3827-3839.

(39) CRC Handbook of Chemistry and Physics, 82nd ed.; Lide, D. R., Editor-in-Chief CRC Press: Boca Raton, FL, 2001.

(40) Atkins, P.; de Paula, J. Atkins' Physical Chemistry, 7th ed.; Oxford University Press: New York, 2002.

(41) (a) Birchall, J. M.; Haszeldine, R. N.; Jones, M. E. Polyfluoroarenes. Part XVII. Some reactions of pentafluorobenzonitrile. J. Chem. Soc. C 1971, 1343-1348. (b) de Pasquale, R. J.; Tamborski, C. Reactions of fluoroaromatic nitriles with sodium pentafluorophenolate. J. Org. Chem. 1968, 33, 1658-1661.

(42) North, A. C. T.; Phillips, D. C.; Mathews, F. S. A semi-empirical method of absorption correction. Acta Crystallogr., Sect. A: Cryst. Phys., Diffr., Theor. Gen. Crystallogr. 1968, 24, 351-359.

(43) COLLECT; Nonius BV: Delft, The Netherlands, 1998.

(44) Otwinowski, Z.; Minor, W. Processing of X-ray Diffraction Data Collected in Oscillation Mode. In Methods in Enzymology, Vol. 276: Macromolecular Crystallography; Carter, C. W., Sweet, R. M., Eds.; Academic Press: New York, 1997; Part A, pp 307-326.

(45) Blessing, R. H. An empirical correction for absorption anisotropy. Acta Crystallogr., Sect. A: Found. Crystallogr. 1995, 51, $33-38$.

(46) SHELXTL; Bruker AXS: Madison, WI, 2015.

(47) Feeder, N.; Less, R. J.; Rawson, J. M.; Oliete, P.; Palacio, F. An unprecedented mode of association in diselenadiazolyl radicals: crystal structures and magnetic properties of $\left[p-\mathrm{XC}_{6} \mathrm{~F}_{4} \mathrm{CNSeSeN}\right]_{2}(\mathrm{X}=\mathrm{Cl}$, Br). Chem. Commun. 2000, 2449-2450.

(48) Jaguar, version 8.7; Schrodinger, Inc.: New York, 2015. Bochevarov, A. D.; Harder, E.; Hughes, T. F.; Greenwood, J. R.;
Braden, D. A.; Philipp, D. M.; Rinaldo, D.; Halls, M. D.; Zhang, J.; Friesner, R. A. Jaguar: A high-performance quantum chemistry software program with strengths in life and materials sciences. Int. J. Quantum Chem. 2013, 113, 2110-2142.

(49) Maestro, version 10.1; Schrodinger LLC: New York, 2015.

(50) Zhao, Y.; Truhlar, D. G. The M06 suite of density functionals for main group thermochemistry, thermochemical kinetics, noncovalent interactions, excited states, and transition elements: two new functionals and systematic testing of four M06-class functionals and 12 other functionals. Theor. Chem. Acc. 2007, 120, 215-241.

(51) Grimme, S.; Antony, J.; Ehrlich, S.; Krieg, H. A consistent and accurate $\mathrm{ab}$ initio parametrization of density functional dispersion correction (DFT-D) for the 94 elements H-Pu. J. Chem. Phys. 2010, $132,154104$.

(52) Peterson, K. A.; Figgen, D.; Goll, E.; Stoll, H.; Dolg, M. Systematically convergent basis sets with relativistic pseudopotentials. II. Small-core pseudopotentials and correlation consistent basis sets for the post-d group 16-18 elements. J. Chem. Phys. 2003, 119, 11113.

(53) Mercury CSD, version 3.3; Build RC5, http://www.ccdc.cam.ac. uk/mercury/. 